\title{
Geografias do saber, Geografias da ignorância
}

Saltando escalas no Sudeste Asiático

Geographies of knowing, geographies of ignorance: jumping scale in Southeast

Asia

Géographies du savoir, géographies de l'ignorance: sauter des échelles en Asie du Sud-Est

Geografías del conocimiento, geografías de la ignorancia: saltar escalas en el sudeste asiático

\section{Willem van Schendel}

\section{(2) OpenEdition}

Journals

Edição electrónica

URL: https://journals.openedition.org/terrabrasilis/8338

DOI: 10.4000/terrabrasilis.8338

ISSN: 2316-7793

Editora

Rede Brasileira de História da Geografia e Geografia Histórica

Refêrencia eletrónica

Willem van Schendel, «Geografias do saber, Geografias da ignorância», Terra Brasilis [Online], 15 | 2021, posto online no dia 31 julho 2021, consultado o 05 dezembro 2022. URL: http://

journals.openedition.org/terrabrasilis/8338 ; DOI: https://doi.org/10.4000/terrabrasilis.8338

Este documento foi criado de forma automática no dia 5 dezembro 2022.

All rights reserved 


\title{
Geografias do saber, Geografias da ignorância
}

\author{
Saltando escalas no Sudeste Asiático
}

Geographies of knowing, geographies of ignorance: jumping scale in Southeast

Asia

Géographies du savoir, géographies de l'ignorance: sauter des échelles en Asie du Sud-Est

Geografías del conocimiento, geografías de la ignorancia: saltar escalas en el sudeste asiático

\section{Willem van Schendel}

\section{NOTA DO EDITOR}

Originalmente publicado na revista Environment and planning D: Society and Space, v. 20, $\mathrm{n}$ 6, dezembro 2002, p. 647-668. A tradução em tela foi realizada pelo professor Daniel De Lucca (UNILAB - campus dos Malês). Agradeço à Willem van Schendel que, de modo tão gentil, autorizou e tornou possível a publicação de seu artigo traduzido para a língua portuguesa. Agradeço também aos estudantes da disciplina "Geografia Política e Geopolíticas do Sul Global", do bacharelado em Relações Internacionais da UNILAB, que, ao longo de vários semestres, colaboraram nas leituras e nos ajustes da tradução, e incentivaram sua publicação.

Sente-se em qualquer barraca de comida e ouça as pessoas ao seu redor. Imagine que você é um especialista em idiomas. Desfrute a fluência de mon-khmer que irradia das mesas ao seu redor. Ouça as crianças na rua gritando em tibeto-burma e a música indo-europeia saindo do rádio. Observe os jornais em cinco escritas diferentes no 
balcão. Encomende o seu almoço de bambu em qualquer um dos vários idiomas e adivinhe onde você está. Bem-vindo ao... Sudeste Asiático?

1 Bem, sim e não. Estamos em Shillong, uma cidade no nordeste da Índia. Isso é Sudeste Asiático? E se sim, por quê? Isso importa? Neste artigo, analiso as 'geografias do saber' que surgiram como resultado da regionalização acadêmica do mundo na segunda metade do século XX. Meu interesse especial é olhar para as margens dessas geografias ou para as margens dos quadros intelectuais conhecidos como 'estudos de área' (area studies). A região em torno de Shillong poderia ser descrita como a fronteira noroeste do Sudeste Asiático, ou como a fronteira nordeste do Sul da Ásia. Eu examino a questão das 'zonas de fronteira' a partir da perspectiva do Sudeste Asiático. Assim, Shillong pode dar suporte a cidades tão dispersas quanto Antananarivo, Trincomalee, Merauke e Kunming.

\section{A disputa pela área}

2 A divisão acadêmica do mundo após a Segunda Guerra Mundial não foi uma campanha militar nem uma campanha administrativa, mas mostrou certa semelhança com a disputa pela África (scramble for Africa) ocorrida duas gerações antes. Primeiro, como precursora, seu ímpeto era político e externo às áreas em questão: emanava da América do Norte e da Europa, que na verdade não eram consideradas 'áreas' em si. Em segundo lugar, resultou em linhas traçadas no mapa do mundo que eram tão ousadas quanto as fronteiras imperiais concebidas na Conferência de Berlim; na verdade, elas frequentemente seguiam as fronteiras imperiais. E terceiro, criava impérios conceituais que eram considerados essencialmente homogêneos e independentes, e menosprezava as realidades sociais preexistentes que atravessavam as fronteiras das 'áreas' recémconcebidas, com exceção daquelas com poderes (neo)coloniais.

3 A disputa pela área levou a uma ancoragem institucional das comunidades acadêmicas em todo o mundo, que treinaram separadamente, engajaram-se em discursos e debates específicos de área, formaram círculos de referência bem estabelecidos e desenvolveram mecanismos e rituais semelhantes para patrulhar suas fronteiras intelectuais. O surgimento do que veio a ser conhecido na América do Norte como 'estudos de área' foi uma fonte de energia, mas também poderia levar ao obscurantismo e, mesmo em suas formas menos rígidas, os estudos de área dificultaram o fluxo de informações entre novas arenas intelectuais. Não é de surpreender que hoje um latinoamericanista que ouve uma conferência de africanistas, ou um estudioso do Oriente Médio entre asianistas do sudeste, se pareça mais com um africano anglófono em um encontro de co-continentais francófonos. Mas mesmo aqueles que se especializam no estudo de áreas do mundo contíguas têm dificuldade em acompanhar o que acontece ao lado. Por exemplo, nas conferências de estudos asiáticos é fácil observar quão fortemente os especialistas de diferentes áreas da Ásia interagem dentro de seus próprios subgrupos regionais e quão pouco eles interagem através deles. Mesmo durante as pausas para café, subgrupos regionais do, por exemplo, Sul da Ásia ou Sudeste Asiático podem persistir, variando de jatis nitidamente delimitados a mandalas vagamente demarcadas. ${ }^{1}$

4 Enquanto isso, a disputa pela área não acabou, continua. À medida que o mundo ultrapassou as realidades políticas de meados do século XIX, que deu origem aos 
estudos de área, os acadêmicos tentaram adaptar suas áreas de acordo com a situação. Isso pode ser visto claramente no surgimento de uma nova área acadêmica, a 'Ásia Central', durante a década de $1990 .^{2}$ As áreas também mudaram porque cada uma se tornou um nexo de mudanças nas relações entre especialistas de área e seus colegas 'do Norte'; essas relações variavam de antagônicas à colaborativas e evoluíram com padrões específicos para cada área. Ao longo de várias gerações, essas redes de relacionamentos se desenvolveram em 'linhagens de área', comunidades de áreas imaginadas cujas disputas e preocupações os aproximam cada vez mais e criam seus próprios sistemas distintos de recompensas, sanções e tabus. Nas sociedades anteriormente colonizadas, os membros da intelligentsia, em rápido desenvolvimento e com ambições internacionais, tinham pouca escolha senão adaptar-se ao molde da área. Além disso, os anos finais do século XX viram o próprio projeto de estudos de área sob fogo, particularmente nos Estados Unidos, que foram mais longe na institucionalização do mesmo. Uma maior conscientização das conexões econômicas e financeiras globais, migração internacional e identidades desterritorializadas e diaspóricas resultou na acusação de que os estudos de área fetichizaram o local - e isso impulsionou os estudos da área a refazer sua afirmação de que a produção de conhecimento sem 'contextualização' era, na melhor das hipóteses, lamentavelmente incompleta. Por fim, a disputa pela área está emergindo gradualmente para aqueles que têm conhecimento especializado da Europa, América do Norte ou Austrália e que são tão envolvidos em estudos de área quanto seus colegas que passam a vida analisando a África ou a América Latina.

\section{0 que é uma área?}

5 Existem três formas principais de compreender uma área acadêmica: como um lugar, como um local de produção de conhecimento e como uma máquina carreirista. Deixeme ilustrar isso tomando o exemplo do Sudeste Asiático.

Muitos descreveram o Sudeste Asiático como um espaço físico, uma região geográfica, uma área que pode ser apontada no globo. ${ }^{3}$ Mas os asianistas do sudeste têm sido notavelmente confusos sobre sua região, que não tem a forma continental distintiva de África ou América Latina e é uma coleção de territórios descontínuos unidos por grandes massas de água. ${ }^{4}$ Como o Sudeste Asiático não tem a evidência geográfica de outras áreas, os asiáticos do Sudeste enfatizaram os laços humanos que fazem da região uma unidade. $\mathrm{Na}$ construção dessa região como um espaço social, a intenção física foi inspirada por uma dose de intenção social mais liberal do que em outros lugares (Smith, 1990).

7 Mas mesmo quando se trata das pessoas que habitam esses territórios, elas são frequentemente descritas em termos do que elas não são. Recentemente, Charles Keyes disse que o Sudeste Asiático é uma região que compreende as "pessoas que vivem a leste da Índia e ao sul da China e ao norte da Austrália" (em Weighing the Balance, 2000: 8). Outros tentaram enfatizar a unidade dos povos da região, sugerindo que eles são caracterizados por "ideias compartilhadas, vidas relacionadas e laços culturais de longa data" (Lewis e Wigen, 1997: 158). Geralmente permanece vago quais laços culturais são realmente considerados decisivos na definição do Sudeste Asiático, embora civilizações, línguas e religiões sejam oferecidas como alternativas. ${ }^{5} \mathrm{O}$ que essas definições compartilham é uma preocupação em apresentar o Sudeste Asiático como um lugar 
geográfico bem delimitado com uma certa consistência interna e um je ne sais quoi regional, uma essência que mesmo os especialistas da área acham difícil de colocar em palavras. ${ }^{6}$ Como resultado, os limites geográficos da região permanecem altamente problemáticos: civilizações, línguas e as religiões nunca coincidiram entre si, nem com as fronteiras políticas contemporâneas que a maioria dos estudiosos do Sudeste Asiático aceita como limites espaciais para sua busca de conhecimento.

Outra maneira de pensar sobre uma área é considerá-la como um espaço simbólico, um local de produção de conhecimento teórico e não como um mero objeto de conhecimento especializado (Morris, em Pesagem, 2000: 11). Neferti Tadiar sugere que:

A 'área' do Sudeste Asiático pode ser entendida mais como uma problematização teórica do que como um objeto de investigação - similar à maneira como entendemos 'estudos culturais' como uma 'área' que oferece novos conjuntos de questões e metodologias. (Weighing the Balance, 2000: 18)

Esta abordagem convida a uma sociologia do conhecimento do Sudeste Asiático. Como o campo do Sudeste Asiático foi constituído pelas predileções, traumas e modas teóricas das instituições acadêmicas norte-americanas, europeias, australianas, japonesas e do Sudeste Asiático? É possível definir a 'problemática teórica' de alguma maneira inequívoca? Qual é o cânon que está sendo ensinado aos novos participantes no campo? Quais são as questões e metodologias que o Sudeste Asiático tem a oferecer para outros campos? E, no contexto mais amplo dos estudos de área, algumas questões cruciais são como um sistema de conhecimento 'regional', com ênfase na especificidade da configuração espacial, em relação a outros sistemas regionais. Quais são as mediações entre estes sistemas e uma abrangente teoria social, e que contribuições os estudos da área podem fazer para uma espacialização contínua dessa teoria? ${ }^{7}$

Finalmente, o Sudeste Asiático pode ser pensado como um espaço institucional, como o nome de um grupo de linhagens acadêmicas transnacionais, círculos de referência, estruturas de autoridade e patronato. Nessa perspectiva, o 'Sudeste Asiático' é tanto uma sociedade global de apoio mútuo quanto uma rede para proteger, promover e validar determinados tipos de especialização. Essa comunidade transnacional é dominada por acadêmicos estabelecidos que atuam como guardiões de uma 'área controlada' do mercado de trabalho, para o qual jovens estagiários selecionados têm acesso. Está em jogo a proteção e, se possível, a expansão do campo dentro das universidades, institutos de pesquisa e centros de formulação de políticas. Estudiosos do Sudeste Asiático (ou qualquer outra área) atuam como lobistas de seu campo. Hoje, uma das preocupações que assola os asianistas do sudeste é o fato de que uma geração de figuras imponentes no campo atingiu a idade da aposentadoria. Teme-se que isso enfraqueça o 'Sudeste Asiático', tanto como um projeto acadêmico quanto como uma máquina carreirista.

\section{A estrutura dos estudos de área}

11 Estudos regionais usam uma metáfora geográfica para legitimar a produção de tipos específicos de conhecimento. Esse conhecimento é estruturado geograficamente e de acordo com as disciplinas acadêmicas. A metáfora geográfica exige que uma 'área' termine onde a próxima começa, mas na realidade os estudos da área se assemelham às mandalas da antiguidade. Reinos de algumas partes do que hoje é chamado de Sudeste Asiático eram poderosos e bem definidos no centro, mas vagos e contestados nas bordas. Eles se expandiam e se contraíam de acordo com a relação com entidades 
políticas vizinhas, e muitas vezes havia áreas entre as quais o status político era indeciso. Estudos de área são assim. Eles não têm limites claros e podem reivindicar novos territórios se lhes convier. Um bom exemplo é o Afeganistão, que é incluído ou omitido do Oriente Médio, Ásia Central e Sul da Ásia.

Alguns estudos da área têm uma forte corte central. Estudos do Sul da Ásia são um exemplo disso. Aqui, a maioria dos estudiosos trabalha na Índia, talvez até no Norte da Índia. Por outro lado, os estudos do Sudeste Asiático parecem formar uma mandala mais multicentrada baseada na aliança de três grandes facções provinciais: os especialistas em Indonésia, Tailândia e Vietnã (Weighing the Balance, 2000: 17-20). As preocupações desses grupos dominam o campo. Eles toleram facções mais fracas nas periferias, por exemplo, aquelas que geram conhecimento acadêmico sobre províncias menores conhecidas como Filipinas, Laos, Malásia ou Birmânia (Mianmar). E depois há as explorações, as fronteiras que separam a região de outras regiões do mundo. No caso do Sudeste Asiático, esses são os lugares liminares mencionados acima: Nordeste da Índia, Yunnan, Sri Lanka, Madagascar, Nova Guiné, e assim por diante. Aqueles que produzem conhecimento especializado sobre esses lugares podem ocasionalmente ser convidados para a corte, mas nunca farão parte da elite do poder. No verdadeiro estilo mandala, essas explorações às vezes são reivindicadas como parte de alguma problemática regional, mas sempre do ponto de vista da corte. As fronteiras raramente valem uma luta real - elas são mais frequentemente esquecidas do que disputadas entre áreas vizinhas.

Da mesma forma, os estudos regionais são estruturados por disciplina, alguns oferecendo status mais elevado (e melhores perspectivas de carreira) do que outros. Uma visão geral recente sugere que a antropologia e a história dominam os estudos do Sudeste Asiático, embora outro grupo de especialistas possa ter elaborado disciplinas mais politicamente orientadas (Weighing the Balance, 2000). Mas claramente, algumas disciplinas têm status baixo. Em termos de planejamento de carreira, seria mais prudente um estudante se formar como antropólogo do que como geógrafo, e ela ou ele deveria ser prudente para escolher Java, em vez do Camboja. Isto não é, naturalmente, porque o estudo geográfico do Camboja é inerentemente menos importante que o estudo antropológico de Java - de fato, pode-se pensar que o impacto de um acadêmico individual na produção de conhecimento pode ser maior em um campo relativamente pouco desenvolvido - mas devido ao sistema de recompensas operacional entre aqueles que definem a relevância da área.

\section{Uma área sem interesse}

A atual reformulação dos estudos de área como um projeto acadêmico pode entristecer muitos discípulos, mas pode ser um alívio para os outros. Eles dão as boas-vindas a uma reconsideração dos contextos, limites e tipos de conhecimento associados à disputa pela área. E não são apenas os 'globalistas' que estão mastigando as coisas. ${ }^{8}$ Muitos outros acham que, em uma tentativa de reconhecimento acadêmico, os proponentes de estudos de área exageraram seu argumento. Sob a bandeira dos estudos da área, determinados feudos acadêmicos foram autorizados a florescer à custa dos outros. Mesmo aqueles que acham que a ideia de atividade acadêmica de base local faz sentido podem se rebelar contra o status quo. Por exemplo, embora muitos especialistas em Sudeste Asiático pensem que sua área é jovem e frágil, esperando ainda para se 
estabelecerem, eles foram colocados na defensiva por recém-chegados que descrevem o Sudeste Asiático como uma 'área tradicional' e que propõem novos contextos regionais, por exemplo, o 'Oceano Índico' ou 'Ásia-Pacífico'. ${ }^{9}$

A construção de espaços em que a atividade humana pensa tomar lugar é sempre contestada, assim como a produção de conhecimento sobre esses espaços sociais, suas "geografias do saber" (Gregory, 1994). Como as metáforas espaciais são importantes na constituição de estudos de área, a visualização desses espaços precisa ser cuidadosamente considerada. Os mapas são as principais ferramentas de representação espacial, e as visões, políticas e posturas implícitas tornaram-se um importante campo de estudo na geografia humana (por exemplo, Harley, 1992). Nos últimos cinquenta anos, a disputa pela área influenciou tanto os cartógrafos quanto o resto de nós, e os atlas geralmente têm mapas com as legendas 'Sudeste Asiático' e 'Sul da Ásia'. Essas visualizações aparentemente objetivas apresentam zonas centrais, bem como periferias - partes do mundo que sempre caem do mapa, desaparecem na extensão das dobras das duas páginas, ou acabam como detalhes. Desta forma, a conveniência cartográfica reforça uma consciência espacial hierárquica, destacando certas áreas do globo e empurrando os outros para as sombras.

Por exemplo, qualquer pessoa interessada em encontrar mapas modernos detalhados mostrando a região que abrange a Birmânia, nordeste da Índia, Bangladesh e partes vizinhas da China sabe que eles não existem. Esta é uma região que é sempre vítima de cirurgia cartográfica. Os mapas do Sudeste Asiático podem não incluir nem as partes norte e oeste da Birmânia, muito menos as áreas vizinhas da Índia e Bangladesh. ${ }^{10} \mathrm{E}$ os mapas do Sul da Ásia não raramente apresentam o nordeste da Índia (e às vezes Bangladesh) como um isolado inconveniente relegado a um detalhe. Fragmentos estranhos do Tibete e de Yunnan podem aparecer em cantos distantes simplesmente devido à necessidade de preencher a forma retangular do mapa.

Este é um exemplo de uma região que é rotineiramente dividida em pedaços por fabricantes de mapas regionais, um tratamento nunca dispensado a 'zonas centrais' (heartlands) como Java ou o vale do Ganges. Não é absurdo argumentar que esta periferização cartográfica é indicativa do status marginal de uma área nos estudos de área, não apenas em termos de distância física para algum núcleo da área imaginado, mas também em termos de relevância percebida para as principais preocupações e problemas que animam o estudo da área - neste caso, Sudeste Asiático, Sul da Ásia, Ásia Central e Ásia do Leste, quatro grandes áreas que supostamente se encontram aqui (Figura 1), ${ }^{11}$ Em outras palavras, esta região, como outras, está amplamente excluída da 'imaginação da área'. Tais regiões são incluídas sob a rubrica acadêmica de uma 'área' apenas para serem ignoradas, alteradas, tornadas ilegíveis. ${ }^{12}$ 


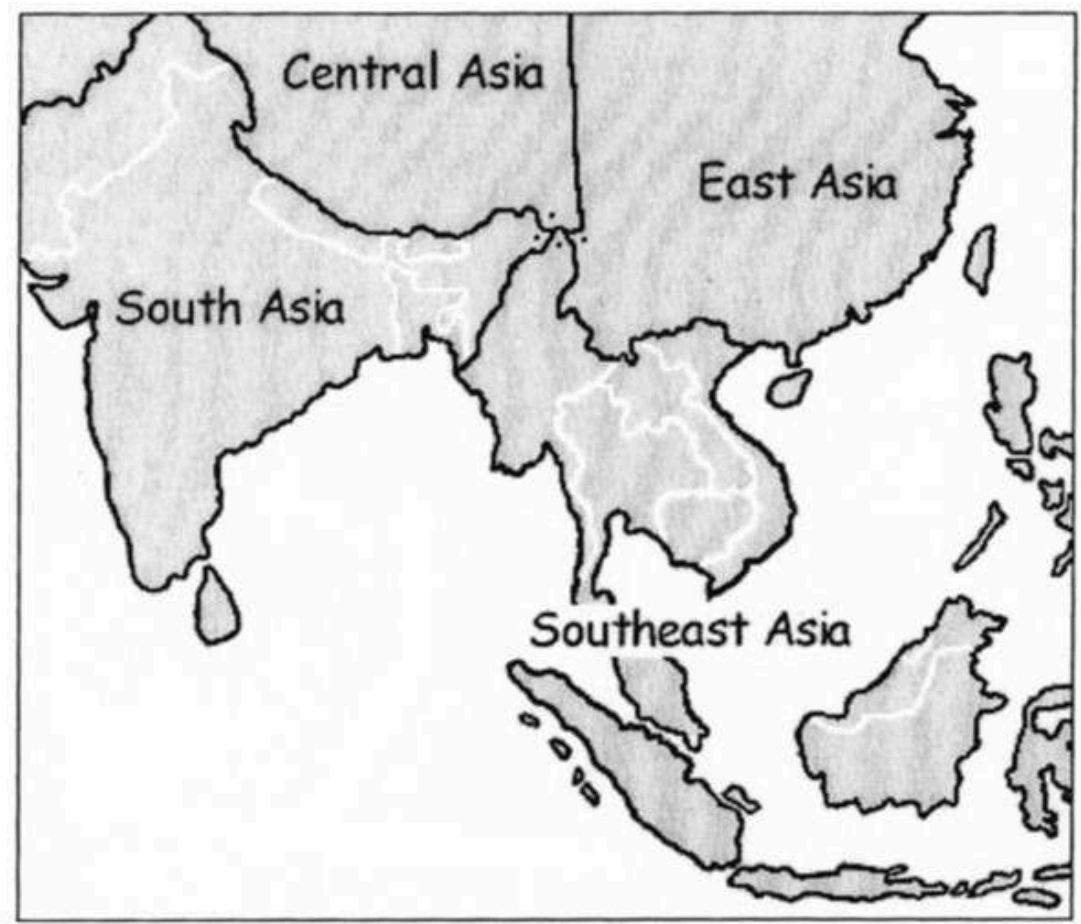

Figure 1. Asia and its areas.

Elaboração própria

Pode ser útil destacar a irrelevância desta região para os estudos de área - e o absurdo dos estudos de área para esta região - considerando o caso de quatro assentamentos no leste do Himalaia, cada um a cerca de $50 \mathrm{~km}$ do outro. Decisões arbitrárias tomadas em estudos distantes e salas de conferências os alocaram em quatro diferentes áreas do mundo: Gohaling está em Yunnan ('Ásia do Leste'), Sakongdan em Burma ('Sudeste Asiático'), Dong está na Índia ('Sul da Ásia'), e Zayu está no Tibete (“Ásia Central”). Eles estão representados por quatro pontos na figura 1. A suposição de que os mais significativos vínculos desses distantes lugares são com os 'núcleos de área' (área core), e não uns com os outros, é um tanto absurda, e a reivindicação dos estudos de área que concebem a unidade das "ideias compartilhadas dos povos, modos de vida afins e laços culturais duradouros" provêm daqui.

Não há, é claro, nada específico sobre os estudos do Sudeste Asiático a esse respeito. Muito da estrutura dos estudos de área levou à periferização de certas regiões e certos tipos de conhecimento. Na próxima seção, eu exploro o problema de uma região sem nome que se estende por quatro áreas acadêmicas atuais. Vamos dar a ela o nome de Zomia. ${ }^{13}$

\section{Por que Zomia não é uma área}

De acordo com o critério de espaço físico usado para apoiar e legitimar os estudos de área, Zomia certamente se qualifica (ver figura 2). Suas "ideias compartilhadas, modos de vida afins e laços culturais duradouros" são múltiplos. Eles incluem afinidades de idioma (por exemplo, línguas tibeto-burma), semelhanças religiosas (por exemplo, religiões comunitárias e, entre as religiões universais, budismo e cristianismo), traços 
culturais (por exemplo, sistemas de parentesco, zonas de dispersão étnica), antigas redes de comércio e condições ecológicas (por exemplo, agricultura de montanha). ${ }^{14}$ No passado, Zomia era um centro de formação estatal (por exemplo, o reino de Nanzhao em Yunnan, os Estados tibetanos, o reino de Ahom em Assam), mas hoje sua principal característica política é que ela é relegada às margens de dez Estados dominados por vales com os quais tem relações antagônicas. ${ }^{15}$ Mesmo que não tenha uma forma (sub) continental agradável, Zomia poderia ter sido definida como uma região geográfica distinta, um objeto de estudo, uma área do mundo.

Figura 2. Uma área de não-interesse: "Zomia"

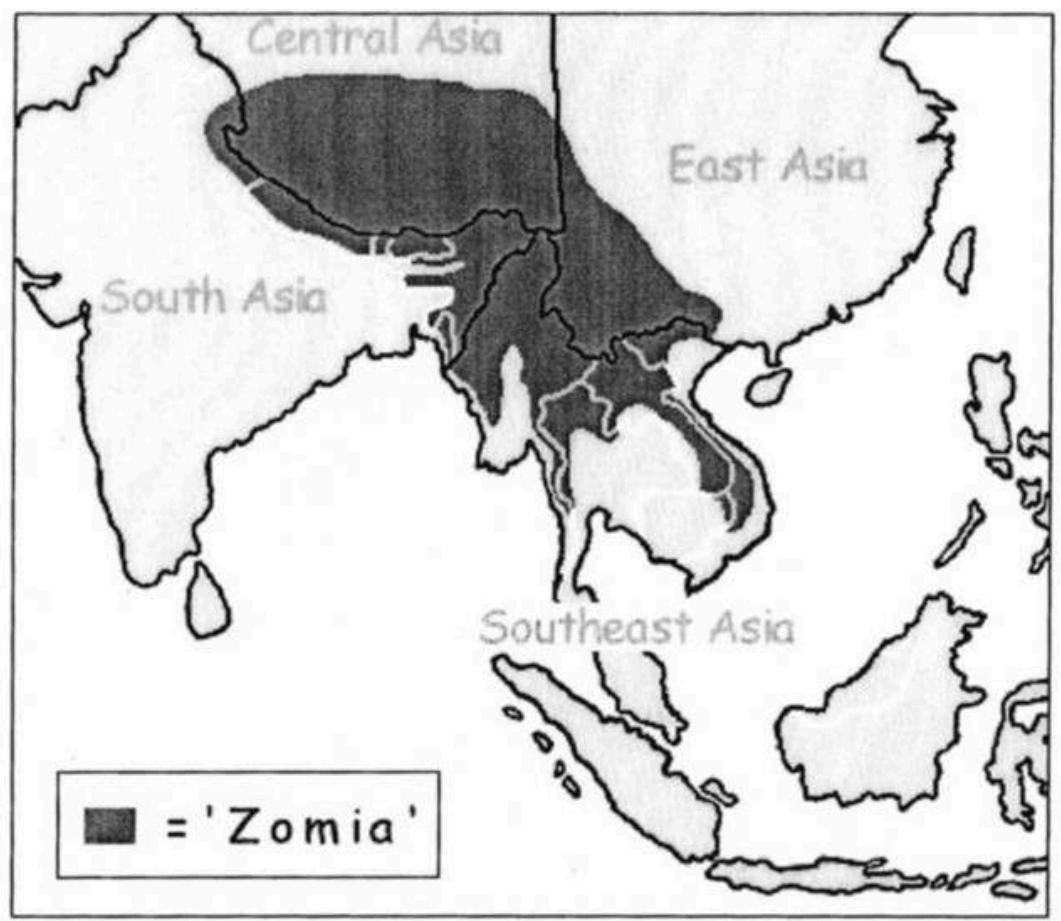

Figure 2. An area of no concern: 'Zomia'.

Elaboração própria

Mas Zomia não se qualifica como uma área se considerarmos o critério de espaço simbólico proposto por Tadiar. Ela não foi trabalhada numa "uma problemática teórica ... oferecendo novos conjuntos de questões e metodologias". Pelo contrário, ela tem declinado abruptamente como um lócus gerador de teoria. Por exemplo, no campo da antropologia, Zomia foi importante até meados do século XX. Produziu influente estudos, como os de Edmund Leach, F. K. Lehman e Christoph von Furer-Haimendorf, em que as relações entre parentesco, estrutura política, identidade étnica e ecologia foram teorizadas. Tais estudos poderiam ter formado a base para uma "problemática teórica" desdobrada, comparável talvez ao que se desenvolveu nos estudos sobre os Andes na segunda metade do século XX. Se os mares podem inspirar os estudiosos a construírem mundos regionais braudelianos, por que não as maiores cadeias de montanhas do mundo? Mas isso não aconteceu. Em vez disso, excelentes estudos de várias partes de Zomia continuaram a serem feitos, mas estes não chamaram a atenção de uma audiência de colegas 'zomianistas', eles não tiveram a ambição de construir uma perspectiva de Zomia que poderia oferecer novos conjuntos de questões e metodologias 
para as ciências sociais (para alguns trabalhos recentes sobre região ver, por exemplo, Atwill, 2000; Chiranan Prasertkul, 1990; Hill, 1998; Jonsson, 1999; Michaud, 2000; van Schendel et al., 2000; van Spengen, 2000; Walker, 1999; Wijeyewardene, 1990). Estes estudos foram escritos para colegas disciplinares que sabiam pouco sobre a região, ou para grupos de especialistas, digamos, mais paroquiais, de Yunnan, nordeste da Índia ou Tibete. Se os especialistas das quatro 'áreas' acadêmicas entre as quais Zomia foi dividida demonstraram algum interesse, isso foi apenas uma benção inesperada. ${ }^{16}$

Em outras palavras, Zomia também falhou em se qualificar como um espaço institucional. Fortes linhagens transnacionais acadêmicas, círculos de referência ou estruturas de autoridade e patrocínio não foram desenvolvidas em torno de Zomia. Ao contrário do 'Sudeste Asiático', ou outras áreas que fizeram isso academicamente, 'Zomia', como outras áreas em potencial, carecia de uma rede de base institucional para proteger, promover e validar a expertise na área. Parece haver três razões principais para isso.

Primeiro, a geopolítica da Guerra Fria mitigou a construção de uma 'Zomia' porque esta região se estendia pelas esferas de influência comunista e capitalista. Ao contrário de outras áreas, nas quais os financiamentos de pesquisa no Norte poderiam ser politicamente apresentados como "conhecendo seu inimigo" ou "guiando jovens nações rumo à democracia", Zomia era uma região confusa e não suficientemente ameaçadora em termos políticos para merecer muita atenção.

Em segundo lugar, Zomia não recobria Estados importantes, mas apenas regiões politicamente marginais de Estados. Esta foi uma desvantagem grave, porque os estudos da área, e toda sua linguagem culturalista, são firmemente estatistas em sua orientação. Todas as áreas de sucesso foram construídas com base em grupos de Estados no meio do século XX, ou mesmo sobre as alianças desses Estados. ${ }^{17}$ As fronteiras do Estado são convencionalmente usadas para demarcar limites externos de cada área. ${ }^{18} \mathrm{~A}$ maioria dos especialistas de área pensa em termos de Estados-nação e identifica-se com o nível estatal e as sociedades específicas do Estado (compare, Reynolds e McVey, 1998). Para o mundo exterior eles se apresentam como especialistas em Indonésia, em vez de, digamos, especialistas no Sudeste Asiático insular ou em Kalimantan. As línguas ensinadas aos especialistas de área que afloram nas universidades do Norte são as línguas "nacionais" dos Estados. ${ }^{19} \mathrm{O}$ nível estatal não só tem prioridade em termos conceituais, mas também é inescapável em termos de financiamento, visibilidade institucional e rede internacional. Esta é uma razão importante porque Zomia, uma área sem Estados independentes, nunca teve uma chance. ${ }^{20}$

Para piorar as coisas, na segunda metade do século XX grande parte de Zomia resistiu aos projetos de construção nacional e formação dos Estados aos quais pertencia. Nesses projetos, os habitantes de terras altas eram frequentemente excluídos dos discursos de cidadania e desempenhavam o papel de não-nacionais, elementos estranhos ou ladrões de recursos florestais do Estado e que poderiam ser resgatados apenas pela assimilação à 'corrente principal' das terras baixas (ver Jonsson, 1998). Em todo Zomia, Estados implementaram políticas de realocação de populações, prevenção de agricultura de montanha, registro de terras, extração de madeira, proteção da vida selvagem, construção de barragens, proteção de bacias hidrográficas e educação nas línguas nacionais, o que levou a novas formas de tensão e competição. Tais formas de 'desenvolvimento' não agiram como uma máquina antipolítica (Ferguson, 1990). Pelo contrário, Zomia ficou caracterizado por uma alta incidência de movimentos regionalistas e separatistas, 'espaços não-estatais', e batalhas discursivas em torno de 
conceitos como 'tribo' e 'povos indígenas' (Scott, 2000). Alguns desses movimentos foram captados pela mídia mundial (que transformou o Tibet, Caxemira e o Triângulo Dourado em nomes familiares), mas a maioria permanece em grande parte desconhecido até mesmo para os especialistas da área. ${ }^{21}$ Por exemplo, a média dos estudiosos do Sul da Ásia teria dificuldade em fornecer uma análise informada sobre as dezenas de movimentos autonomistas altamente ativos em Assam e em outros estados do Nordeste da Índia, alguns deles com mais de cinquenta anos de existência.

Como resultado dessa relação antagônica e da fraqueza do controle estatal sobre grandes áreas de Zomia, vários desses Estados restringiram severamente a entrada de forasteiros..$^{22}$ Desta forma, a marginalidade estatal também mitigou o florescimento dos estudos de área de Zomia. Especialistas de área que trabalharam livremente na região nos anos 1940 e 1950 acharam cada vez mais difícil obter acesso para si e seus alunos em décadas mais recentes. Embora essas restrições não fossem uniformes e agora pareçam estar diminuindo na maior parte de Zomia, esta história de acesso difícil, vigilância do Estado e perigo físico tem se demonstrado um contratempo para o estudo da região.

Em terceiro lugar, Zomia não contou com o apoio de dois influentes grupos universitários que foram instrumentos na construção acadêmica dos estudos de área no Norte. Um grupo consistiu em 'especialistas coloniais' - intelectuais encarregados dos antigos cursos de formação para funcionários coloniais, bem como seus estagiários - que procuravam novos papéis no final da era colonial. Muitos deles procuraram reinventar-se como especialistas sensíveis à área em desenvolvimento, e eles auxiliaram fortemente o reempacotamento de seus conhecimentos e habilidades na forma de estudos de área. 0 outro grupo era o de 'especialistas em civilização', estudiosos que estudaram 'civilizações' não-ocidentais, especialmente através de seus legados textuais, e eram conhecidos como indologistas, islamologistas, sinologistas ou, mais genericamente, orientalistas. Esses especialistas estavam ansiosos para garantir que quaisquer novos estudos de área fossem reedificados em torno das construções civilizacionais às quais se dedicaram. No caso do 'Sul da Ásia' e do 'Oriente Médio', especialistas coloniais e civilizacionais participaram quase em igual medida na criação de sua 'área', enquanto em no caso da 'Ásia do Leste' os especialistas em civilização dominaram e, no 'Sudeste Asiático' os especialistas coloniais dominaram. Os especialistas em Sudeste Asiático estavam bem conscientes de que os especialistas em civilização forneciam prestígio indispensável a uma 'área' e faziam questão de salientar que, embora poucos especialistas em civilização considerassem sua 'área' uma das maiores civilizações do mundo, "as tradições culturais do Sudeste Asiático são ricas e dinâmicas demais para serem reflexões posteriores em campos dedicados às 'grandes' tradições do mundo" (Keyes, 1992: 18). ${ }^{23} \mathrm{E}$ ao contrário, por exemplo, do Sul Ásia, o Sudeste Asiático permaneceu uma área fracamente construída porque não desenvolveu raízes locais fortes:

o Sudeste Asiático não é, em geral, um domínio significativo para o estudo em países da região, onde as histórias nacionais são a principal preocupação, e tem sido principalmente um construto euro-japonês. (Reynolds, 1995: 420; compare Tarling, 1999: xviii ${ }^{24}$

Mas Zomia estava mais desfavorecida do que isso. Era uma região do interior que esteve à margem, ou mesmo além do alcance efetivo, da influência externa que animou vívidos debates nos estudos do Sul da Ásia e do Sudeste Asiático: a conquista colonial marítima europeia. À Zomia faltava um forte lobby de especialistas coloniais. Também não 
desenvolveu uma poderosa persona civilizacional nas universidades do Norte, porque estava às margens ou além do impacto 'civilizacional' da Índia, da China e do Islã. E, por esse motivo, tinha muitos poucos especialistas em civilização para defendê-la.

Como resultado destas três desvantagens - ambiguidade política, ausência de fortes centros de formação estatal, e insuficiente influência acadêmica - os potenciais zomianistas perderam a disputa pela área após a Segunda Guerra Mundial. Eles não conseguiram criar um nicho para si e para as relações sociais e redes que estudaram. Como sua região foi esquartejada e eles foram impedidos de se reproduzirem intelectualmente, a produção de conhecimento sobre esta região desacelerou e a nova distribuição de área definiu seu trabalho com menos consequências. Cinquenta anos depois, essas deficiências persistem, mesmo embora a visibilidade geopolítica de Zomia tenha mudado um pouco com o surgimento de produção de heroína em grande escala na área, a descoberta de recursos minerais, turismo, e uma nova preocupação com questões ambientais e indígenas. Mas essas mudanças não foram suficientes para desfazer o lugar marginal de Zomia na hierarquia do conhecimento, ou para reviver produção de conhecimento, e muito menos dar suporte a reivindicações viáveis para seu estudo de área. ${ }^{25}$

\section{A escala dos estudos de área}

O exemplo de Zomia mostra que os estudos de área que se desenvolveram durante a Guerra Fria não eram exatamente o que pareciam ser: empreendimentos conjuntos de praticantes das ciências sociais e das humanidades para avançar na compreensão de um conhecimento abrangente das diferentes regiões do mundo. Eles eram tanto mais quanto menos que isso. Como expressões de uma geografia particular do poder, eles eram instrumentos para naturalizar arranjos geopolíticos da época. Como expressões de certos interesses acadêmicos e disciplinas, eles eram instrumentos em estratégias institucionais buscando financiamentos, estudantes, empregos e prestígio. E eles contribuíram para uma certa guetização de insights críticos visto que os estudos de área tendiam para o modelo coorporativo. Especialistas em área foram recompensados por 'conhecer seu próprio lugar': treinando em centros de estudos da área, reconhecendo diferenças dentro do contexto mais amplo da unidade de sua área, contribuindo com suas descobertas em seminários e periódicos específicos na área, e dedicando suas carreiras ao estudo de sua área de atuação e treinamento, sem necessariamente acompanhar os desenvolvimentos intelectuais ao lado.

31 As poderosas imagens geográficas dos estudos da área enfatizavam a contiguidade ou proximidade na análise social e sugeriam uma certa homogeneidade em cada área que poderia ser projetada de volta no tempo. Esta retórica, usada livremente para legitimar estudos de área, raramente foi posta à prova. Um problema fundamental é que os estudos da área produziram muitos 'especialistas sub-regionais' (para usar um termo empregado por Wolters, 1999: 213), mas pouquíssimos verdadeiros especialistas em áreas: acadêmicos com uma compreensão completa de toda a área de sua escolha. Em vez disso, certas sub-regiões e temas bem pesquisados inevitavelmente foram retratados como de alguma forma incorporando a essência da área e, portanto, capazes de serem apresentados como partes pro toto. Desta forma, estudos de área foram um grande impulso para o estudo dessas sub-regiões e temas, mas pouco fizeram por outras, tornando estas definitivamente menos visíveis. Como uma imagem, então, a 
área foi muito mais significativa para certas preocupações, comparações e interesses do que a outras. ${ }^{26}$

Hoje, as questões importantes já não parecem ser a busca pela cultura do Sudeste Asiático, a essência da civilização islâmica ou o espírito da Ásia Oriental. Tais perguntas essencialistas não se encaixam facilmente com o fascínio pelo hibridismo, transnacionalismo e transformação global, temas que tem animado tantos projetos de pesquisa recentes. A compartimentação geográfica tornou-se um inconveniente. Podem ser ouvidos clamores para superar o "fetiche de contiguidade dos esquemas regionais prevalecentes" e para:

visualizar 'regiões' descontínuas que podem assumir a forma espacial de tramas, arquipélagos, anéis vazios ou retalhos ... o atrito da distância é muito menor que costumava ser; fluxos de capital tanto quanto migrações humanas podem criar e recriar rapidamente conexões profundas entre lugares distantes. Como resultado, algumas das agregações socioespaciais mais poderosas de nossos dias simplesmente não podem ser mapeadas como territórios únicos e delimitados ... A geografia da vida social no final do século XX ultrapassou não só os contornos do mapa do mundo pós-guerra, mas também muitas das convenções pelas quais representamos padrões espaciais em imagem e texto. (Lewis e Wigen, 1997: 190-200)

Em outras palavras, o que está sendo defendido é "uma mudança decisiva em relação ao que podemos chamar geografias dos 'traços' para o que poderíamos chamar de geografias dos 'processos', que mantêm a força heurística por trás das áreas imaginárias, mas as trata como artefatos contingentes e variáveis (Appadurai, 2000: 7). Esta preocupação em repensar a espacialidade da vida social pode se beneficiar de contribuições recentes que criticam as ciências sociais por sua prática generalizada de tratar o espaço como "autoevidente, não problemático e teoricamente desnecessário", e de ver "a história como a variável independente, o ator, e a geografia como dependente - o terreno sobre o qual os eventos "tomam lugar", o campo dentro do qual a história se desdobra (Smith, 1992: 61, 63).

Rejeitando as categorias espaciais como ontologicamente dadas - como recipientes de historicidade estática e atemporal (Brenner, 1999: 46) - os teóricos da geografia humana estão no processo de desenvolver uma teoria da escala geográfica. ${ }^{27}$ Eles enfatizam que as diferentes escalas, ou níveis de representação espacial, que usamos em nossas análises sociais - por exemplo, locais, nacionais, regionais, globais - não são de forma alguma fixados, mas são socialmente construídos e devem ser entendidos como "impasses temporários em uma transformação perpétua... de luta pelo poder socioespacial" (Swyngedouw, 1997: 169). ${ }^{28}$ Afirmando que as escalas são sempre resoluções geográficas provisórias de lutas pelo poder, eles nos convidam a considerar como as escalas são historicamente produzidas, estabilizadas e transformadas. ${ }^{29}$ Certamente, configurações escalares - ou 'ajustes escalares' (Smith, 1995) - podem adquirir vida longa e se tornar tão estabilizadas quanto os 'andaimes' de certas formas de poder e controle que nós as experimentamos como naturais e permanentes. Mas elas são sempre finitas. ${ }^{30}$

Como vimos, a 'região mundial' ou 'área' é uma escala relativamente nova, pelo menos como uma representação espacial que é imaginada para ser uma componente de uma contínua trama abrangendo o globo. Ela também é contestada. A abordagem construcionista para contornar a escala, discutida acima, pode ajudar no estudo mais sistemático de quais geometrias de poder inseriram o 'reescalonamento' que produziu a 
configuração dos estudos de área após a Segunda Guerra Mundial. Ao mesmo tempo, este esforço pode ajudar a ampliar a teoria da escala geográfica de três maneiras.

Primeiro, embora se reconheça que "escalas geográficas são produzidas, contestadas e transformadas através de uma imensa gama de processos sociopolíticos e discursivos, estratégias e lutas que não podem ser derivadas de qualquer dinâmica" (Brenner, 1998: 461), os teóricos da escala até agora deram esmagadora atenção ao papel da produção capitalista e do Estado na construção de escala. ${ }^{31}$ A construção dos estudos de área, no entanto, parece ter ocorrido relativamente independente da agência do capital, trabalho e Estado. Por esta razão, a construção de estudos de área pode fornecer um bom argumento para explorar o significado, no processo de reescalonamento, dos fatores socioculturais e discursivos além dos socioeconômicos.

Em segundo lugar, os teóricos da escala estudaram certas escalas mais do que outras. As escalas urbana, nacional e global receberam mais atenção, com contribuições recentes chamando a atenção para a casa e o corpo. Mas as escalas entre o nacional e o global permanecem sub-expostas, e neste ponto a escala das regiões mundiais é um útil campo de investigação adicional.

E terceiro, a teoria da construção social de escala ainda é fortemente Norte-Atlântica e de sabor urbano. Trata de sociedades altamente industrializadas ('núcleos') e toma seus casos de estudos da Europa e América do Norte, ou seja, de apenas uma ou duas 'regiões mundiais'. Tal seletividade pode ser lida como um exemplo particular da 'política de escala' na medida em que transmite implicitamente que o capitalismo industrial, os poderosos Estados burocráticos e as construções 'ocidentais' da escala são mais importantes (para uma rara exceção, ver Kelly, 1997). Isto é exatamente o que muitos praticantes de estudos de área têm longamente questionado. É essencial que uma teoria da escala leve em consideração as muitas maneiras em que a política da escala que emana de várias partes do mundo, moldou nossa condição contemporânea. Como uma era Euro-norte-americana de regiões mundiais imaginadas chega ao fim,

atores em diferentes regiões agora têm elaborados interesses e capacidades na construção de retratos do mundo cuja interação afeta os processos globais. Então, o mundo pode consistir de regiões (vistas processualmente), mas as regiões também imaginam seus próprios mundos. (Appadurai 2000: 10) ${ }^{32}$

O que é necessário, então, é um novo léxico socioespacial que nos permita analisar adequadamente estes desenvolvimentos (Lewis e Wigen, 1997: 192). As metáforas geográficas dos estudos de área têm sido usadas para visualizar e naturalizar espaços sociais particulares, bem como escalas particulares de análise. Uma questão importante é como esses espaços metafóricos se relacionam ao espaço material. Até que ponto eles resultam em um territorialismo metodológico que analisa formas e escalas espaciais como sendo auto-enclausuradas e delimitadas territorialmente como unidades geográficas (Brenner, 1999: 45-46)? Quais são as geografias do saber que resultaram dos estudos de área? E quais as geografias da ignorância?

Neste artigo, observei que os especialistas da área não se preocuparam o que suas metáforas tornam invisíveis. Eu fiz isso invocando um espaço material (Zomia) que foi tornado periférico pelo surgimento de fortes comunidades de especialistas de área do Sul, Centro, Leste e Sudeste Asiático ${ }^{33}$. Sem dúvida, a questão de invisibilidade pode ser mais bem abordada a partir de estudos do Sudeste Asiático, porque estes têm produzido uma literatura muito introspectiva e profunda sobre si mesmo - por comparação, outros estudos de área são muito mais complacentes. ${ }^{34}$ Mas até mesmo os especialistas 
em Sudeste Asiático são pouco preocupados com a exploração de como sua metáfora geográfica determina como eles visualizam o espaço e aquilo que eles não podem ver. Não há, no meu conhecimento, debates espirituosos sobre os efeitos de privilegiar as 'zonas centrais' (heartland), a demarcação precisa da área, a delimitação de seus alcances mais distantes, ou a necessidade de explorar e abranger suas margens. Pelo contrário, a maneira mais elegante como os textos fundamentais tratam tais assuntos sugere talvez essa precisa demarcação seja considerada tanto trivial quanto pedante. Mas vale a pena levar mais a sério a intenção geográfica dos estudos de área $\mathrm{e}$ considerar outras perspectivas que podem transformar as áreas 'de dentro para fora' [para usar um termo empregado de um modo um tanto diferente, por Wyatt (1997)]. Um exame da noção geográfica de distância pode ser particularmente útil na abertura de novas linhas de pesquisa.

\section{Lugares distantes}

41 A ideia de afastamento foi obviamente importante na criação de estudos de área, uma vez que eram lugares distantes que precisavam ser mais bem compreendidos nos centros mundiais de poder. A distância era tanto uma realidade física quanto uma metáfora cultural, e os estudos da área ofereciam geografias do conhecimento a longa distância. Meio século depois, as tecnologias de comunicação mudaram o cenário. A distância não é mais exatamente a tirana que já foi e uma consciência aguda do encolhimento do mundo se espalhou amplamente, e desigualmente, através do globo. Isto é verdade não apenas entre regiões do mundo, mas também dentro delas [para o tremendo encurtamento dos tempos de viagem na fronteira entre a Birmânia e a China desde meados da década de 1980, ver Porter (1995: 36-40)]. Muito está sendo escrito sobre as formas em que novas tecnologias de transporte, mídia e redes digitais forjam novas comunidades tanto local como globalmente e como estas podem ser estudadas adequadamente olhando redes que não estão contidas nos territórios fronteiriços dos Estados e das áreas. A distância não é mais entendida principalmente em termos geográficos e culturais. É cada vez mais visto como um atributo social: certos grupos de pessoas têm melhor acesso a tecnologias para superar a distância do que outras.

Os estudos de área e suas problemáticas são inadequadas para lidar com relações humanas transbordando os limites da área, e temos que elaborar perspectivas mais adequadas para englobar estas. Embora os estudos de globalização enfatizem o crescimento mundial das redes (novas mídias, fluxos de capital, diásporas, organizações internacionais, 'cidades globais'), há muitas outras passagens de fronteira que precisam ser entendidas. É um erro supor que os cruzamentos mais reveladores são aqueles entre o Ocidente e o resto. Compreensões de vínculos globais precisam emergir com força das trocas diretas entre estudiosos que estudam diferentes partes do 'Sul'.

Uma tarefa importante na reestruturação da academia mundial no início do século XXI é a construção de instituições que permitam acadêmicos treinados no estudo de uma determinada área superar tais fronteiras e se comunicar de forma mais significativa através delas em todos os níveis: a produção de conhecimento teórico, foco temático, metodologia e habilidades empíricas. Precisamos de versões acadêmicas de estratégias para 'saltar escalas' (Smith,1992: 60), que nos permita “contornar ou desmantelar formas de organização territorial historicamente entrincheiradas e suas morfologias escalares associadas" (Brenner, 1999: 62). ${ }^{35}$ 


\section{Cruzando fronteiras regionais}

44 a fim de destacar vínculos inter-regionais mais do que identidades regionais, mas é raro que estes clamores sejam traduzidos em arranjos institucionais duradouros que contribuem para a colaboração transregional inovadora (por exemplo, Volkman, 1998). Centros acadêmicos de estudos de área podem ser lugares notavelmente inóspitos para especialistas de outras áreas e a colaboração transregional quase nunca está no topo de sua agenda. A colaboração na forma de projetos transregionais ocorre, no entanto, por exemplo, entre o Sudeste Asiático e o Leste da Ásia, e entre o Sudeste Asiático e a Orla do Pacífico ${ }^{36}$. Tais geografias do conhecimento transregional são muito mais fracas, ou mesmo ausentes, entre especialistas do Sudeste Asiático e Ásia Central, ou Sudeste Asiático e Sul da Ásia ${ }^{37}$.

Dois temas parecem ser especialmente úteis para iniciar uma colaboração acadêmica significativa em vínculos inter-regionais. Ambos têm a ver com perspectivas sobre o espaço, distância e mobilidade - com os mapas conceituais que usamos para ordenar a vida social. o primeiro tema é a fronteira, o segundo é o fluxo de objetos, pessoas e ideias.

\section{Zonas de fronteira (borderlands)}

Os alcances externos de 'áreas' são menos conhecidos porque a maioria das pesquisas tem sido concentrada em problemas que lidam com o que é percebido como a heartland e centro de poder e mudança. ${ }^{38}$ Hoje, enquanto cientistas sociais estão se distanciando da estrutura espacial que Eric Wolf certa vez chamou de "um mundo de bolas de bilhar socioculturais" e estão tomando conhecimento da natureza processual de todas as geografias de vida social, tais 'heartlands' e 'centros' parecem cada vez mais artificiais [(Wolf, 1982: 17; para uma análise da fragmentação de uma heartland industrial nos EUA, ver Smith e Dennis (1997)]. E como o poder político é visto mais em termos de práticas sociais cotidianas do que primordialmente incorporadas nas instituições e processos da política formal, modos convencionais de estudar Estados, nações e sociedades estão sob revisão. ${ }^{39}$ Uma crescente literatura sobre fronteiras internacionais sugere que se pode aprender sobre centros de poder observando suas periferias. Muitos problemas que atualmente chamam a atenção dos cientistas sociais - transnacionalismo, cidadania e alteridade, acomodação étnica, hibridismo, interpretação de escalas e práticas regulatórias, economias subterrâneas e conflitos internacionais - sempre foram parte integrante dos meios fronteiriços (Baud e van Schendel, 1997; Donnan e Wilson, 1999; Martinnez, 1994).

$\mathrm{Na}$ pesquisa em ciências sociais, a tendência de longa data tem sido ver as unidades nomeadas (Estados, sociedades e culturas) como separadas e distintas, cada uma com sua própria estrutura e fronteiras externas. No final do século 20, pensando em termos de separação de 'áreas', seguiu-se esse exemplo. Mas as áreas são ainda menos bolas de bilhar do que os Estados. A concentração de mais pesquisas sobre o que os especialistas $\mathrm{da}$ área aprenderam a considerar como fronteiras de sua área podem ajudar a superar o que sua geografia do conhecimento tem obscurecido e marginalizado: as muitas interconexões entre esses pacotes dinâmicos de relacionamentos. Tentativas atuais de

Terra Brasilis, 15 | 2021 
refazer os estudos da área estão começando a captar isso. Eles apresentam as fronteiras entre as áreas como 'zonas intersticiais' que funcionam "quase como regiões híbridas em seu próprio direito” (Lewis e Wigen, 1997: 188, 203).

\section{Fluxos}

Uma maneira promissora de desenvolver um sentido historicamente mais completo e teoricamente mais rico das interconexões entre as áreas é começar a partir de objetos e pessoas em movimento transnacional (ou 'transareal'). Estamos conscientes da enorme importância da mobilidade transnacional, mas ainda faltam conceitos, teorias e medidas para estudar adequadamente. Mesmo algo tão direto quanto o tamanho desses fluxos é frequentemente desconhecido, especialmente o tamanho das mercadorias que são declaradas ilícitas por alguns ou todos os Estados. Para dar apenas um exemplo, o comércio mundial de drogas ilegais foi estimado em algo entre US \$500 e US \$1000 bilhões por ano, ou seja, aproximadamente o mesmo tamanho que o PIB combinado de todos os Estados do Sudeste Asiático. ${ }^{40} \mathrm{Se}$ acrescentarmos a isso fluxos ilícitos (tráfico de armas pequenas, trabalho não documentado, materiais nucleares, animais, órgãos humanos, obras de arte e assim por diante), bem como os fluxos que aparecem como comércio na contabilidade nacional e internacional, podemos começar a ter uma noção do papel dos fluxos na criação de geografias dos processos.

49 À medida que esses fluxos se movem pelas localidades, contribuindo para sua ascensão e queda, eles interagem com Estados e organizações não-estatais. Os padrões resultantes da interação são complexos e mudam com o tempo. Os Estados podem proibir certos fluxos, dando origem a economias subversivas, ou podem encorajá-las, dando origem a alianças entre Estados e organizações não-estatais. Fluxos podem de repente mudar de curso como resultado de eventos como guerra, crise econômica, ou a demanda do consumidor em colapso. Em qualquer caso, os fluxos transnacionais e as redes, movimentos, empresas e organizações que os promovem, entram e saem das arenas que os especialistas da área criaram para si próprios. 0 mapeamento desses fluxos só pode ser feito apropriadamente, envolvendo a expertise de especialistas de mais de uma área, mas, por outro lado, os especialistas da área precisam desenvolver um novo léxico socioespacial, a fim de comunicar eficazmente uns com os outros sobre os fluxos.

50 O estudo das áreas de fronteira às vezes sobrepõe-se ao dos fluxos transnacionais, e pode ser particularmente recompensador concentrar novas investigações neste ponto de encontro. No caso das fronteiras do Norte do Sudeste Asiático, novas pesquisas podem basear-se em alguns esforços anteriores, concentrados principalmente na região onde Yunnan e o 'Sudeste Asiático continental' se encontram (por exemplo, Vorasakdi Mahatdhanobol, 1998; Wijeyewardene, 1993). Uma abordagem que foi desenvolvida aqui é a de analisar os fluxos nas fronteiras em termos de uma política de mobilidade uma reunião de práticas regulatórias usadas para iniciar e controlar mobilidade e interconexão. Como Andrew Walker demonstra em um recente estudo de comerciantes no rio Mekong, os Estados territoriais se encontram nas fronteiras, mas a regulação dos fluxos transnacionais não é apenas de domínio dos Estados. Atores não estatais são participantes ativos em uma política de mobilidade que pode estimular ou dificultar bens e pessoas através das fronteiras do Estado (e da 'área') (Walker, 1999). 
51 Em contraste, as fronteiras do noroeste foram negligenciadas tanto por estudantes do Sul da Ásia quanto do Sudeste Asiático, e estão agora entre as regiões menos conhecidas do mundo. E, no entanto, fluxos transnacionais consideráveis passam por aqui. A maioria foi proibida por um ou mais dos Estados envolvidos, e são, portanto, no mínimo parcialmente subterrâneos. Entre os fluxos mais visíveis estão armas pequenas e explosivos, heroína e os produtos químicos necessários para sua produção, trabalhadores migrantes, guerrilheiros e refugiados ${ }^{41}$. As formas pelas quais os Estados interagem com esses fluxos - pela militarização em larga escala, programas de transmigração, substituição de produção agrícola, tributação e assim por diante - e as maneiras pelas quais esses fluxos interagem com os Estados - infiltrando-se em suas burocracias, forjando ligações com os detentores do poder e influenciando as suas políticas - são frequentemente mais visíveis nas regiões de fronteira.

Claramente, 'Estado' e 'área' são muito limitantes como escalas se quisermos analisar os fluxos transnacionais. Além do fato de que os fluxos não respeitam essas escalas, lutas sobre a regulação dos fluxos estão influenciando escalas continuadamente, mudando sua importância ou criando outras inteiramente novas (compare, Swyngedouw, 1997: 169). Tais 'geografias dos processos' em curso podem ser bem observadas nas fronteiras. Tome o fluxo de armas pequenas através das zonas de fronteira do Sul e Sudeste Asiático. A própria fronteira está associada a numerosas rebeliões armadas, e elas, e os exércitos estatais que as opõem, usam rifles de assalto, metralhadoras e lançadores de foguetes produzidos nos Estados Unidos, Rússia, Israel ou Bélgica. ${ }^{42}$ Mas as armas também são usadas para proteger fluxos ilícitos de heroína e muitas outras mercadorias quando passam em suas fronteiras a caminho de mercados distantes. Os cientistas sociais têm pouca informação sobre o fluxo de armas na região e nós sabemos ainda menos sobre como eles reformulam as práticas regulatórias nas fronteiras ou redimensionam os Estados nesta região. O fluxo de pequenas armas para o Oeste através Sudeste Asiático continental está documentado até certo ponto (Pasuk Phongpaichit et al., 1998: 127-154), e, em uma recente pesquisa mundial sobre armas pequenas, Bangladesh foi identificada como um importante depósito de armas pequenas para o Sul e Sudeste Asiático:

Bangladesh é um importante ponto de trânsito para as armas na região. Pequenas armas chegam do Bangladesh, do Afeganistão e do Paquistão, de um lado, e da Tailândia, Singapura, Myanmar e Camboja, por outro lado. De lá, as armas geralmente vão para o norte para os rebeldes no nordeste da Índia ou para o sul para os LTTE [no Sri Lanka]. (Small Arms Survey 2001: 182) ${ }^{43}$

53 Mas o uso do Estado, ou mesmo a 'área', como a escala de análise para os fluxos dificilmente ajuda a circunscrever os relacionamentos relevantes. É em localidades particulares da fronteira de Bangladesh que essas transferências ocorrem e pode ser mais útil nos focarmos nos 'regimes de regulação', as práticas regulatórias que criam essas localidades. Por exemplo, a insignificante cidade fronteiriça de Teknaf e o porto de pesca próximo do Bazar de Cox, no Sudeste do Bangladesh, tornou-se um grande nó de uma rede transnacional de comércio de armas. Eles recebem armas e munições da Birmânia e além-mar, e as encaminha para destinos na Índia, Bangladesh e além. Que política de mobilidade e que práticas regulatórias se combinaram para individualizar essas duas localidades? Que novas geometrias de poder social emanam destas localidades e como estas contribuem para os processos de redimensionamento, empoderado alguns e desempoderando outros? Estes são os tipos de perguntas que podem nos levar a respostas sobre as geografias dos processos que estão em curso. 


\section{Tramas, arquipélagos, anéis vazios e retalhos?} processos em que regiões podem tomar formas espaciais desconhecidas - tramas, arquipélagos, anéis vazios, retalhos - devemos considerar que futuro há para o estudo de áreas convencionais como Sudeste Asiático. Em resposta ao desafio das perspectivas globais, um repensar de sistemas 'regionais' de conhecimento estão em andamento. Os espaços sociais imaginados pelos estudos da área e a escala de estudos de área estão sendo reexaminados assim como a espacialização da teoria social entra num novo terreno não mapeado. Quanto mais nos tornamos conscientes das maneiras pelas quais a vida contemporânea frustra pressupostos convencionais de ideias e modos de vida territorialmente compartilhados, mais essas suposições também estão sendo desafiadas pelo passado. E quanto mais percebemos como as forças sociais dos espaços 'marginais' podem resistir, e até rearranjar, estruturas de poder estabelecidas, mais devemos abandonar o heartlandismo e estadocentrismo inerente à prática dos estudos de área.

Claramente, os estudos da área não serão abandonados. Não há dúvida de que as fortes comunidades acadêmicas construídas em torno de estudos de área continuarão a produzir conhecimento sobre problemáticas de área. Mas quem vai achar essas problemáticas relevantes? Os futuros estudiosos irão olhá-las como expressões de alguma feição passada, ou talvez como formas de um orientalismo do início do século XXI? Certamente, a força dos estudos de área é a sua insistência na especificidade das configurações espaciais. Mas a sua fraqueza é a imposição de limites espaciais que não fazem sentido, exceto possivelmente a partir de um ponto de vista da heartland. Para superar as geografias resultantes da ignorância, precisamos estudar configurações espaciais de outras perspectivas também. Como o ajuste escalar estabelecido após a $2^{\mathrm{a}}$ Guerra Mundial está sendo transformado, o mundo está sendo reterritorializado e é necessário reimaginar configurações espaciais emergentes entre o nacional e o global. As sugestões feitas neste artigo apontam para três possíveis alternativas.

Primeiro, há a construção de regiões transversais às convencionais. Esta abordagem é inovadora na medida em que reúne espaços e práticas sociais que agora são academicamente marginais e divididas. Mas esta abordagem também é susceptível de replicar as distorções dos estudos de área, criando novas zonas centrais (heartlands) e marginais, bem como comunidades de estudiosos que tendem a permanecer dentro de suas novas arenas. Uma segunda opção é procurar configurações espaciais que não sejam territórios compactos. $\mathrm{O}$ estudo das zonas fronteiriças nos fornece um favo de mel mundial dos espaços materiais contíguos com configurações sociais muito distintas e nenhuma heartland particular. Essa combinação de especificidade espacial e lastro global faz das fronteiras uma região mundial de um tipo diferente e estudá-la corretamente requer o envolvimento dos estudiosos de todas as 'áreas' convencionais. A terceira opção vai além. Os fluxos transnacionais formam configurações espaciais, mas sua arquitetura é mais efêmera: se altera, às vezes rapidamente, em tamanho, compacidade e complexidade.

O estudo desses fluxos, especialmente os que são clandestinos devido a proibição do Estado, é notoriamente difícil, mesmo se ancorado em pontos específicos no espaço ou no tempo. É aqui que a especialidade da área é absolutamente indispensável para os 'estudos dos fluxos': ela pode fornecer o estudo de fluxos completamente baseados em 
espaços e tempos específicos. Por sua vez, o estudo das geografias dos processos (e das práticas regulatórias que as consolidam e dissolvem) ajudará os especialistas de área a saltar de escala, romper a crisálida repartição das áreas que ocorreu após a Segunda Guerra Mundial, e desenvolver novos conceitos de espaço regional.

Enquanto isso, de volta a Shillong, você terminou seu almoço - cozinhado por um imigrante ilegal do Nepal e servida em placas contrabandeadas da China. Pegue um jornal hindi do balcão e leia sobre os rifles vindo do Bangladesh, o preço dos rubis birmaneses, uma mulher de Shillong que se saiu bem no Canadá e as mortes de drogas no mês passado. A música no rádio parou e um anúncio é feito sobre a celebração do Dia da República da Índia. Duas mulheres jovens na próxima mesa riem baixo e escavam em seus noodles tailandeses. Você caminha para o sol, perguntando-se sobre espaços, escalas e fluxos.

\section{BIBLIOGRAFIA}

Agnew, J. Regions on the mind does not equal regions of the mind. Progress in Human Geography, v. 23, n. 1, 1999, p. 91-96.

Anderson, B. The Spectre of Comparisons: Nationalism, Southeast Asia, and the World. London: Verso, 1998.

Appadurai, A. Globalization and Area Studies: The Future of a False Opposition. Amsterdam: Centre for Asian Studies Amsterdam, 2000.

Ascherson, N. Black Sea. London: Jonathan Cape, 1995.

Atwill, D. Reorienting the Yunnan world: shifting conceptions of ethnicity, boundaries and trade. paper for the workshop "Beyond Borders: (Il)licit Flows of Objects, People and Ideas", Centre d'Études et Recherches Internationales, Paris, 1-4 July 2000.

Baud, M; van Schendel, W. Toward a comparative history of borderlands. Journal of World History, v. 8, 1997, p. 211-242.

Brenner, N. Between fixity and motion: accumulation, territorial organization and the historical geography of spatial scales. Environment and Planning D: Society and Space, v. 16, 1998, p. 459-481.

Brenner, Neil. Beyond state-centrism? Space, territoriality, and geographical scale in globalization studies. Theory and Society, v. 28, 1999, p. 39-78.

Carter, G. F. China's Southwest and Burma's Changing Political Geography (1979-1996). Ann Arbor, MI: University Microfilms International, 1999.

Chakraborty, P. The Inner-line Regulation of the North-east (Together with the Chin Hills Regulation Etc. and with Commentaries). Titagarh: Linkman Publication, 1995.

Chiranan, Prasertkul. Yunnan Trade in the Nineteenth Century: Southwest China's Cross Boundaries Functional System. Bangkok: Institute of Asian Studies, Chulalongkorn University, 1990.

Christian, D. Inner Eurasia as a unit of world history. Journal of World History, v. 5, 1994, p. 173-211.

Cox, K. R. Spaces of dependence, spaces of engagement and the politics of scale, or: looking for local politics. Political Geography, 1998, v. 17, p. 1-23. 
Dirlik, A. The Asia-Pacific idea: reality and representation in the invention of a regional structure. Journal of World History, v. 3, 1992, p. 55-79.

Donnan, H.; Wilson, T. M. Borders: Frontiers of Identity, Nation and State. Oxford: Berg, 1999.

Dowdy, W. L. The Indian Ocean region as concept and reality. In: Dowdy, W. L.; Trood, R. B. (Eds.). The Indian Ocean: Perspectives on a Strategic Arena. Durham, NC: Duke University Press, 1985, p 3-23.

Emmerson, D. K. Southeast Asia: what's in a name? Journal of Southeast Asian Studies, v. 15, 1984, p. $1-21$.

Ferguson, J. The Anti-politics Machine: 'Development', Depolitization, and Bureaucratic Power in Lesotho. Cambridge: Cambridge University Press, 1990.

Gilmore, D. On Mediterranean studies. Current Anthropology, v. 31, 1990, p. 395-396.

Gregory, D. Geographical Imaginations. Oxford: Blackwell, 1994.

Harley, J. B. Deconstructing the map. In: Barnes, T. J.; Duncan, J. (Eds). Writing Worlds: Discourse, Text and Metaphor in the Representation of Landscape. London: Routledge, 1992, p 231-247.

Harvey, D. Justice, Nature and the Geography of Difference. Oxford: Blackwell, 1996.

Hill, A. M. Merchants and Migrants: Ethnicity and Trade Among Yunnanese Chinese in Southeast Asia. New Haven, CT: Yale University Southeast Asia Studies, 1998.

Hill, L; Hitchcock, M. Anthropology. In: Halib, M.; Huxley, T. An Introduction to Southeast Asian Studies. London: IB Tauris, 1996, p. 11-45.

Hirschman, C.; Keyes C. F.; Hutterer, K. (Eds.). Southeast Asian Studies in the Balance: Reflections from America. Ann Arbor, MI: The Association for Asian Studies, 1992.

Howitt, R. Scale as relation: musical metaphors of geographical scale. Area, v. 30, 1998, p. 49-58.

Jonsson, H. Forest products and peoples: upland groups, Thai politics and regional space. Sojourn, v. 13, 1998, p. 1-37.

Jonsson, H. Shifting Social Landscape: Mien (Yao) Upland Communities and Histories in State-client Settings. Ann Arbor, MI: University Microfilms Incorporated, 1999.

Kelly, P. F. Globalization, power and the politics of scale in the Philippines. Geoforum, v. 28, 1997, p. 151-171.

Keyes, C. F. A conference at Wingspread and rethinking Southeast Asian studies. In: Hischman, C; Keyes, C. F.; Hutterer, K. (Eds.). Southeast Asian Studies in the Balance: Reflections from America (The Association for Asian Studies, Ann Arbor, MI), 1992, p. 2-4.

Leach, E. Political Systems of Highland Burma: A Study of Kachin Social Structure. London: London School of Economics and Political Science, 1954.

Leach, E. The frontiers of 'Burma'. Comparative Studies in Society and History, v. 3, 1961, p. 49-68.

Lehman, F. K. The Structure of Chin Society: A Tribal People of Burma Adapted to a NonWestern Civilization. Champaign, IL: University of Illinois Press, 1963.

Lefebvre, H. De l'État [The state] 4 volumes. Paris : Union Ge"ne"rale d'Eèditions, 1976-1978.

Lefebvre, H. The Production of Space. Oxford: Blackwell, 1991.

Lewis, M. W.; Wigen, K. E. The Myth of Continents: A Critique of Metageography. Berkeley, CA: University of California Press, 1997. 
McKinnon, J.; Michaud, J. Introduction: Montagnard domain in the South-East Asian massif. In: Michaud, J. (Ed.). Turbulent Times and Enduring Peoples: Mountain Minorities in the South-East Asian Massif. Richmond: Curzon, 2000, p. 1-25.

McVey, R. Introduction: local voices, central power. In: McVey, R. (Ed.). Southeast Asian Transitions: Approaches through Social History. New Haven, CT: Yale University Press, 1978, p. 1-27.

Marston, S. A. The social construction of scale. Progress in Human Geography, v. 24, 2000, p. 219-242.

Martínez, O. J. The dynamics of border interaction: new approaches to border analysis. In: Schofield, C. H. (Ed.). Global Boundaries: World Boundaries, v. 1. London: Routledge, 1994, p. 1-15.

Means, G, P. Human sacrifice and slavery in the 'unadministered' areas of Upper Burma during the colonial era. Sojourn, v. 15, 2000, p. 184-221.

Michaud, J. (Ed.). Turbulent Times and Enduring Peoples: Mountain Minorities in the SouthEast Asian Massif. Richmond: Curzon), 2000.

Palat, R. A. Fragmented visions: excavating the future of area studies in a post-American world. Review, v. 19, 1996, p. 269-315.

Pasuk, Phongpaichit; Sungsidh, Piriyarangsan; Nualnoi, Treerat. Guns, Girls, Gambling, Ganja: Thailand's Illegal Economy and Public Policy. Chiangmai: Silkworm Books, 1998.

Pina-Cabral, J. The Mediterranean as a category of regional comparison: a critical view. Current Anthropology, v. 30, 1989, p. 399-406.

Pluvier, J. M. South-East Asia from Colonialism to Independence. Kuala Lumpur: Oxford University Press, 1974.

Porter, D. J. Wheeling and Dealing: HIV and Development on the Shan State Borders of Myanmar. New York: UNDP, 1995.

Reid, A. Southeast Asia in the Age of Commerce, 1450-1680, v. 1. The Land Below the Winds. New Haven, CT: Yale University Press, 1988.

Reid, A. Southeast Asia in the Age of Commerce, 1450-1680, v. 2. Expansion and Crisis. New Haven, CT: Yale University Press, 1993.

Reynolds, C. J. A new look at old Southeast Asia. Journal of Asian Studies, v. 54, 1995, p. 419-446.

Reynolds, C. J.; McVey, R. Southeast Asian Studies: Reorientations; The Frank H. Golay Memorial Lectures 2 and 3. Ithaca, NY: Cornell University Southeast Asia Program, 1998.

Rigg, J.; Scott, P. The rise of the naga: the changing geography of South-East Asia, 1965-90. In: Chapman, G. P.; Baker, K. M. (Ed.). The Changing Geography of Asia. London: Routledge, 1992, p 74-121.

Robb, P. The colonial state and constructions of Indian identity: an example on the northeast frontier in the 1880s. Modern Asian Studies, v. 31, 1997, p. 245-283.

Scott, J. C. Seeing Like a State: How Certain Schemes to Improve the Human Condition Have Failed. New Haven, CT: Yale University Press, 1998.

Scott, J. C. Hill and valley in Southeast Asia, or ... why civilizations can't climb hills. Paper for the workshop Beyond Borders: (Il)licit Flows of Objects, People and Ideas, Centre d'Eètudes et Recherches Internationales, Paris, 1-4 July 2000. 
Shapiro, M.; Schiffman, H. F. Language and Society in South Asia. Dordrecht: Foris Publications, 1983.

Small Arms. Survey 2001: Profiling the Problem 2001. Oxford: Oxford University Press, 2001.

Smith, N. Uneven Development: Nature, Capital and the Production of Space. 2nd edition. Oxford: Blackwell, 1990.

Smith, N. Contours of a spatialized politics: homeless vehicles and the production of geographical scale. Social Text, v. 33, 1992, p. 55-81.

Smith, N. Remaking scale: competition and cooperation in prenational and postnational Europe. In: Eskelinen, H.; Snickars, F. (Eds.). Competitive European Peripheries. Berlin: Springer, 1995, p. 59-74.

Smith, N.; Dennis, W. The restructuring of geographical scale: coalescence and fragmentation of the Northern core region. Economic Geography, v. 63, 1997, p. 160-182.

Sobhan, R. Transforming Eastern South Asia: Building Growth Zones for Economic Cooperation., Dhaka: Centre for Policy Dialogue and the University Press Limited, 1999.

Sobhan, R. Rediscovering the Southern Silk Route: Integrating Asia's Transport Infrastructure. Dhaka: University Press, 2000.

Soja E, Postmodern Geographies: The Reassertion of Space in Critical Social Theory. London: University Press, 1989.

Solheim, W. G. II. 'Southeast Asia': what's in a name', another point of view. Journal of Southeast Asian Studies, v. 16, 1985, p. 141-147.

Soucek, S. A History of Inner Asia. Cambridge: Cambridge University Press, 2000.

Swyngedouw, E. Excluding the other: the production of scale and scaled politics. In: Lee, R.; Wills, J. (Eds.). Geographies of Economies. London: Arnold, 1997, p. 167-176.

Tarling, N. A Concise History of Southeast Asia. New York: Praeger, 1961.

Tarling, N. (Ed.). The Cambridge History of Southeast Asia. 2nd edition. Cambridge: Cambridge University Press, two volumes, 1999.

Tate, D. J. M. The Making of Modern South-East Asia, v. 1. Kuala Lumpur: Oxford University Press, 1971.

Tate, D. J. M. The Making of Modern South-East Asia, v. 2. Kuala Lumpur: Oxford University Press, 1979.

van Schendel, W.; Mey, W.; Dewan, A. K. The Chittagong Hill Tracts: Living in a Borderland. Bangkok: White Lotus, 2000.

van Spengen, W. Tibetan Border Worlds: A Geohistorical Analysis of Trade and Traders. London: Kegan Paul, 2000.

Volkman, T. A. Crossing borders: the case of area studies - in an increasingly interconnected world, the discipline of area studies is at a turning point. Ford Foundation Report, v. 29, 1998, p. 28-29.

von Furer-Haimendorf, C. The Naked Nagas. London: Methuen, 1939.

von Furer-Haimendorf, C. The Sherpas of Nepal: Buddhist Highlanders. London: John Murray, 1964.

Vorasakdi, Mahatdhanobol. Chinese Women in the Thai Sex Trade. Bangkok: Institute of Asian

Studies, Chulalongkorn University, 1998. 
Walker, A. The Legend of the Golden Boat: Regulation, Trade and Traders in the Borderlands of Laos, Thailand, Burma and China. London: Curzon Press. 1999.

Weighing the Balance. Southeast Asian Studies Ten Years After - Held in New York City, November 15 and December 10, 1999, 2000. Proceedings of Two Meetings (Social Science Research Council, New York).

Wheeler, J. H.; Kostbade, J. T. Essentials of World Regional Geography. Fort Worth, TX: Harcourt Brace Jovanovich, 2007.

Wijeyewardene, G. Ethnic Groups Across National Boundaries in Mainland Southeast Asia. Singapore: Institute of Southeast Asian Studies, 1990.

Wijeyewardene, G. Southeast Asian borders: report of a seminar held at the Australian National University, 28-30, October 1993. Thai - Yunnan Project Newsletter, n. 23, 1993, p. 28-30.

Williams, L. E. Southeast Asia: A History. New York: Oxford University Press, 1976.

Wolf, E. R. Europe and the People Without History. Berkeley, CA: University of California Press, 1982.

Wolters, O. W. History, Culture, and Region in Southeast Asian. Singapore, Ithaca, NY: Revised edition Cornell University Southeast Asia Program Publications, in cooperation with the Institute of Southeast Asian Studies, 1999.

Wyatt, D. K. Southeast Asia 'inside out', 1300-1800: a perspective from the interior. Modern Asian Studies, v. 31, 1997, p. 689-709.

\section{NOTAS}

1. Entre os estudiosos do Sul da Ásia, o termo 'jati' é usado para denotar grupos endogâmicos com limites sociais claros ('subcastas'); Os especialistas do Sudeste Asiático usam o termo 'mandala' para se referir a entidades políticas pré-coloniais cuja extensão geográfica e fronteiras eram vagamente definidas.

2. Esta área ainda é uma unidade instável, conforme indicado pela confusão terminológica em torno dela. Muitos escritos sobre a Ásia Central tratam exclusivamente da antiga parte soviética, agora dividida entre cinco estados independentes a Leste do Mar Cáspio. Alguns, no entanto, também incluem os Estados ex-soviéticos no Cáucaso. Lewis e Wigen (1997: 176-181) propõem uma área muito maior, cobrindo os estados a Leste do mar Cáspio, Xinjiang, Mongólia e Tibete. Outros questionam, como Soucek (2000), que argumenta que apenas a parte ex-soviética é a 'Ásia Central', e que a região que Lewis e Wigen propõem deve ser chamada de 'Ásia Interior', ou Christian (1994), que propõe o termo 'Eurásia Interior'. No Journal of Asian Studies, os livros são revisados sob o título 'China e Ásia Interior'.

3. Agnew (1999: 92) descreveu essa abordagem como aquela dos realistas, para os quais "a 'região' tipicamente evoca a ideia de um bloco de espaço homogêneo que tem uma característica distintiva persistente devido a suas características físicas e culturais. A alegação é de que existe 'lá fora' no mundo." Eles se encontram em uma 'desafortunada oposição' com os construcionistas, "que consideram todas as regiões como meras invenções do observador cujas definições dizem mais sobre a posição político-social. desse observador do que os fenômenos que as regiões pretendem classificar".

4. Especialistas do Sudeste Asiático têm discutido a natureza e a identidade de sua área, bem como suas próprias conquistas e deficiências, numa medida completamente desconhecida por seus colegas especializados, por exemplo, no Sul da Ásia (ver Emmerson, 1984; Hirschman et al., 1992; Solheim, 1985; Weighing the Balance, 2000). 
5. Mas os critérios culturalistas tornam as definições geográficas altamente problemáticas. Como Hill e Hitchcock (1996: 12) argumentam, “em termos etnográficos, partes do nordeste da Índia, sul da China e Taiwan podem pertencer ao Sudeste Asiático, enquanto Irian Jaya tem muito em comum com o mundo melanésio".

6. Isto é um tanto enigmático para os não iniciados - como é colocado no prefácio do The Cambridge History of Southeast Asia: "O Sudeste Asiático tem sido visto como um todo, embora outros termos tenham sido usados para isso. O título Sudeste Asiático, tornando-se corrente durante a Segunda Guerra Mundial, foi aceito como reconhecendo a unidade da região, sem prejulgar a natureza dessa unidade. No entanto, pesquisas acadêmicas e escritos mostraram que não é mera expressão geográfica" (Tarling, 1999, volume 1: xi).

7. Muito trabalho nesse campo está sendo feito na geografia humana, uma disciplina que ainda é pouco integrada aos estudos de área (por exemplo, ver Harvey, 1996; Gregory, 1994; Smith, 1990; Soja, 1989).

8. Para um ataque feroz e um retrato dos estudos de área como "idiográfico, autorreferencial, ... ancorado em uma epistemologia anacrônica, positivista", ver Palat (1996: 301).

9. Ambas as áreas, que atravessam o 'Sudeste Asiático', ganharam ocorrência considerável no final do século XX. Seu surgimento deveu-se muito às ideias de Fernand Braudel sobre o Mediterrâneo, que Reid $(1988,1993)$ também aplicou ao Sudeste Asiático. Para uma declaração programática sobre a área do Oceano Índico, ver Dowdy (1985). Desde então, revistas acadêmicas (como The Indian Ocean Review) e institutos de pesquisa (por exemplo, o Center for Indian Ocean Regional Studies, Curtin University of Technology, em Perth) tomaram a área como foco. Sobre o Anel do Pacífico / Bacia do Pacífico / Ásia-Pacífico, ver, por exemplo, Dirlik (1992).

10. Nos trabalhos sobre Sudeste Asiático, os mapas não são raramente montados para excluir as regiões aparentemente irrelevantes do norte da Birmânia. Essa tendência é particularmente notável nos mapas do Sudeste Asiático 'moderno'. À medida que os asiáticos do sudeste passam do início da história para os períodos colonial e pós-colonial, eles parecem se tornar menos inclusivos e gravitar em direção a uma persuasão 'litorânea' (ver, por exemplo, mapas em Pluvier, 1974; Rigg e Scott, 1992; Tate, 1971). 1979; Williams, 1976).

11. Compare com o mapa em Lewis e Wigen (1997: 187).

12. Scott (1998) explora a relação entre poder, conhecimento e 'legibilidade' para Estados - mas a ideia de legibilidade pode ser aplicada a outros grupos estruturados de observadores, como especialistas de área.

13. Ele é derivado de zomi, um termo para os montanheses em várias línguas Chin-Mizo-Kuki faladas na Birmânia, Índia e Bangladesh. Os lingüistas classificam essas línguas como pertencentes à grande família de línguas tibeto-burma faladas em toda Zomia [Caxemira, Norte da Índia, Nepal, Tibete, Sikkim, Butão, Nordeste da Índia, serras de Chittagong (Bangladesh), Birmânia, Yunnan e Sichuan (China), Tailândia, Laos e Vietnã]. Não inesperadamente, em vista da compartimentação acadêmica dessa vasta região, “com poucas exceções, essas línguas são descritas de maneira muito inadequada na literatura acadêmica ... a situação caótica que atualmente existe em relação às relações mútuas e afinidades entre essas línguas não é de surpreender". (Shapiro e Schiffman, 1983: 115; compare com: <http://linguistics.berkeley.edu/ stedt/html/STfamily.html>).

14. Se isso aparecer como uma estranha variedade de características, é bom lembrar que os traços geralmente apresentados para definir uma área tendem a ser uma "confusão não reconhecida de categorias fisiográficas, culturais e políticas" (Lewis e Wigen, 1997: 197). A este respeito, uma reivindicação de 'Zomia' com base nos critérios mencionados acima não é mais forçosa que a do Oriente Médio, baseada em "uma 'encruzilhada', aridez, riqueza petrolífera, cultura islâmica, língua árabe, contribuições iniciais à civilização e uma história recente de conflitos ferozes" (Wheeler e Kostbade, 1993: 196); para uma revisão crítica, ver Lewis e Wigen (1997: 197, compare com a página 195). 
15. A única exceção é o Butão, em que o poder do Estado reside formalmente em uma elite de Zomia, mas essa elite é fortemente controlada pela elite estatal da Índia. Os dez Estados são China, Vietnã, Laos, Camboja, Tailândia, Birmânia, Índia, Bangladesh, Butão e Nepal.

16. Nos estudos do Sudeste Asiático, está em curso uma tentativa de defender um 'domínio montagnard' [habitantes das montanhas]. Em sua revisão da literatura, McKinnon e Michaud (2000: 2) mostram que há estudos para casos isolados, mas quase nenhum que aborda "mais de uma sociedade montanhosa do Maciço [do Sudeste Asiático] e dá a este último o status de uma unidade espacial e social supranacional coerente".

17. Muitos estudiosos do Sudeste Asiático tacitamente limitaram seu alcance aos países da ASEAN (Association Southeast Asia Nations, que por décadas excluíram o Laos, Birmânia, Vietnã, Camboja e Timor-Leste), assim como os especialistas em Sul da Ásia depois com a SAARC (South Asian Association for Regional Cooperation). Áreas com "insuficiência estatal" têm dificuldade em se estabelecer como áreas acadêmicas - por exemplo, 'Ásia Central', que não poderia emergir como uma área até que se desenvolvesse uma soberania independente na forma dos Estados póssoviéticos da região.

18. Muitas vezes existem curiosas inconsistências. A definição de Tarling (1961: xi) da área parecia francamente estatista: “O termo 'Sudeste Asiático' é usado para descrever um grupo de Estados que se encontram entre as grandes massas terrestres da Índia e da China”. Mas, quando chegou à lista de territórios, ele incluiu não apenas oito Estados, mas também as Ilhas Andaman e Nicobar (que pertencem à Índia).

19. O ambicioso e bem-sucedido programa de ensino de idiomas SEASSI (Southeast Asian Studies Summer Institute) nos EUA é um bom exemplo. Aqui, vietnamita, tagalog, laosiano, khmer, tailandês, indonésio e burma são ensinados; estas são todas línguas estatais. Além disso, dentre centenas de línguas não estatais no Sudeste Asiático, duas delas podem ser aprendidas aqui: hmong e javanesa. A maioria dos estudos de área do Sul da Ásia não consegue se igualar essa riqueza. Eles tendem a se concentrar em duas línguas estatais da região, o hindi e o urdu (mas não oferecem as línguas oficiais do Nepal, Bangladesh, Butão, Sri Lanka ou Maldivas), e duas línguas 'clássicas', o sânscrito e o tâmil.

20. O baixo nível de 'visibilidade estatal' de Zomia também se reflete na ausência de qualquer aliança estatal na região. Não houve ASEANs, SEATOs ou SAARCs. Foi na década de 1980 que as primeiras iniciativas patrocinadas pelos Estados materializaram, por exemplo, o ICIMOD (The International Centre for Integrated Mountain Development), lançado em 1983 e preocupado com a rede em Zomia. Seu foco inicial no Hindu Kush, na região do Himalaia, foi gradualmente ampliado através da Rede de Montanhas da Ásia-Pacífico (ver <http://www.icimod.org/>).

21. Alguns especialistas da área seguiram o que Wolters (1999: 160-162), em uma interessante autocrítica, chama de "presunção da elite das terras baixas" e o "preconceito dos habitantes das terras baixas" em relação às terras altas, que são percebidas como um sertão (hinterland) distante e isolado, com um baixo status na ordem mundial.

22. Por exemplo, a Índia mantém a colonial 'Linha Regulação Interior' (Inner Line Regulation) que impede a entrada, no Nordeste da Índia (isto é, os estados de Assam, Meghalaya, Sikkim, Arunachal Pradesh, Tripura, Mizoram, Manipur e Nagaland), não apenas de estrangeiros nacionais, mas também de indianos não-locais, incluindo pesquisadores (ver Chakraborty, 1995; Robb, 1997).

23. Os especialistas do Sudeste Asiático procuraram explicar por que sua região era uma retardatária entre as áreas mundiais. Anderson (1998: 4-5) apresenta quatro razões para isso: a ausência de um poder hegemônico histórico, a heterogeneidade religiosa, uma história segmentada do imperialismo; e estando numa posição mais remota dos centros imperiais. Na região, ele sugere, um senso de unidade foi formado por três fatores: ocupação japonesa durante a Segunda Guerra Mundial, a luta armada contra o imperialismo e a experiência da Guerra Fria, 
na qual o Sudeste Asiático era a região mais instável dos EUA, que temia aquisições comunistas ali.

24. Mais recentemente, Anderson colocou deste modo: "Como um significado imaginário, [o Sudeste Asiático] teve uma vida muito curta, mais curta que a minha. Não é de surpreender que a sua nomeação venha de fora, e que mesmo hoje muitos poucos entre os quase 500 milhões de almas que habitam suas cerca de 1.750 .000 milhas quadradas de terra (para não falar de água) se consideram 'asiáticos do sudeste' (1998: 3).

25. Nos últimos anos, proeminentes estudiosos do Sudeste Asiático têm repetidamente retratado seu campo como enfraquecido, relativamente invisível e academicamente marginalizado. É bom manter um senso de perspectiva aqui. Quando os especialistas em Sudeste Asiático descrevem sua região como "a mais insubstancial das áreas do mundo", eles obviamente não têm em mente regiões como Zomia ou Ásia Central. Da mesma forma, quando eles se preocupam com uma ameaça de "hiato geracional" nos estudos do Sudeste Asiático, é desanimador comparar isso com o verdadeiro "abismo geracional" que se abriu no estudo de Zomia (Weighing the Balance 2000: $13,14,16)$.

26. Uma dessas preocupações era construir uma identidade de área em adição, ou em oposição, às identidades nacionais sendo fortemente promovidas durante o mesmo período (para o Sudeste da Ásia, ver Emmerson, 1984: 21). Tanto os nacionalistas quanto os especialistas da área usaram a história como uma ferramenta poderosa nesse esforço. Por isso, um livro com o título de The History of Southeast Asia é tão programático como, digamos, o milagre da invenção, 5000 years of Pakistan. $O$ esforço de estudos de área ao longo do último meio século é talvez mais bem resumido em outro título de livro, In Search of Southeast Asia: A Modern History.

27. Uma importante fonte de inspiração para essa abordagem é o trabalho de Lefebvre (especialmente 1976-78; 1991). Para uma visão geral, veja Marston (2000).

28. "Essas lutas mudam a importância e o papel de certas escalas geográficas, reafirmam a importância de outras e, às vezes, criam novas escalas significativas, mas - mais importante essas redefinições de escala alteram e expressam mudanças na geometria do poder social fortalecendo o poder e o controle de alguns enquanto tiram o poder dos outros" (Swyngedouw, 1997: 169).

29. Como argumenta Howitt (1998), é crucial entender a escala como relação, e não apenas em termos de tamanho e nível.

30. Para uma história esquemática dos ajustes escalares desde o final do século XIX, ver Brenner (1998).

31. Para uma primeira tentativa de incorporar reprodução e consumo social, ver Marston (2000).

32. Kelly asserts that in the Philippines such alternative imaginations of the global do exist, although largely beyond the bounds of institutional politics (1997: 169).

33. Essa periferização é menos proeminente entre os especialistas de área preocupados com a arqueologia e com o início da história da Ásia, mas se torna mais notável entre especialistas com interesse na história recente e no período contemporâneo. Jonsson (1998) argumenta que a invisibilidade dos habitantes das terras altas nos estudos do Sudeste Asiático também resultou das tendências da teorização antropológica que privilegiam os governantes e os camponeses como protagonistas políticos e econômicos.

34. Os debates sobre a utilidade da construção de áreas particulares ocasionalmente explodem, por exemplo, a breve briga no Mediterrâneo entre Pina-Cabral (1989) e Gilmore (1990), ou o retrato de Ascherson (1995) do Mar Negro.

35. Na busca das políticas de escala, grupos de pessoas geralmente saltam escalas organizando-se em uma escala mais global, mas os saltos de escala também podem levar à mobilização em escala mais local (compare Cox, 1998). 
36. Por exemplo, o Thai-Yunnan Project criado na Australian National University em 1987, ou o programa de pesquisa 'International Social Organization in East and Southeast Asia: Qiaoxiang ties in the 20th century', iniciado pelo Internacional Institute of Asian Studies na Holanda em 1997.

37. Nesse aspecto, os acadêmicos parecem estar bem atrás do tempo da política. Tomemos, por exemplo, redes de Estado-para-Estado, que por muito tempo pareciam se encaixar no modo regional, mas cada vez mais se estendem através das fronteiras de área para formar redes comerciais e de produção econômica multi-Estatais (triângulos de crescimento, quadriláteros) e infraestruturas multi-Estatais (Asian Highway, Trans Asian Railway, reabertura da estrada de Stillwell de Assam à Yunnan). Esses são exemplos de toda uma gama de distâncias entre o 'local' e o 'global' que precisam ser exploradas tanto conceitual quanto empiricamente. Ver Sobhan (1999; 2000) sobre a zona de crescimento e transporte trans-regional da BBIMN (Bhutan, Bangladesh, Índia, Mianmar, Nepal), e Carter (1999) sobre a zona de crescimento da China e da Birmânia.

38. Nesse sentido, as zonas fronteiriças são tão remotas para os especialistas da área quanto as 'áreas não administradas' eram para as autoridades coloniais (ver Means, 2000).

39. Como observou McVey (1978: 3), os historiadores voltaram sua atenção para "os níveis mais baixos da sociedade, tanto como arenas da experiência intrinsecamente significativas quanto como pontos básicos essenciais para a compreensão da mudança social". Essa atenção pode ser ampliada focando-se mais sistematicamente em arenas de experiência longe dos centros (heartland) da área, conforme são definidos atualmente.

40. A Conferência das Nações Unidas sobre Crime Organizado Global (1994) apresentou a estimativa de cerca de US $\$ 500$ bilhões por ano, mas outras estimativas respeitáveis apontam o número correto em duas vezes esse valor. O PIB de todo o Sudeste Asiático no mesmo período foi estimado em cerca de US $\$ 700$ bilhões.

41. Décadas de insurreição no noroeste da Birmânia, no nordeste da Índia e no sudeste de Bangladesh transformaram a região em um mercado de armas de longa data, com importantes rotas de abastecimento através da Tailândia, China e Baía de Bengala (via portos de Bangladesh). A heroína do Triângulo Dourado é usada para suprir um mercado consumidor em rápida expansão no Sul da Ásia. Nos últimos anos, muitas refinarias de heroína foram transferidas da fronteira entre a Tailândia e a Birmânia (Estado de Shan) para as fronteiras entre a Índia e a Birmânia (Estado de Chin), e os portos e aeroportos do Sul da Ásia estão sendo cada vez mais usados para transportar heroína para os mercados europeus. Os movimentos populacionais na região são bastante grandes: milhões de bengaleses deslocaram-se ilegalmente para o Nordeste da Índia em busca de trabalho e terra, refugiados e trabalhadores migrantes da Birmânia mudaram-se para a Índia e Bangladesh (e para lá, os Rohingyas da Birmânia formam agora grandes comunidades em Bangladesh, no Paquistão e no Golfo). E os insurgentes de todos os países da região passam habitualmente pelas fronteiras, escondendo-se das forças de segurança, trocando dinheiro ou drogas por armas e estabelecendo alianças com potências estrangeiras.

42. Grupos insurgentes ao longo da fronteira entre o Sudeste Asiático e o Sul da Ásia incluem Arakanese, Jumma, Chin, Meithei, Naga e vários outros grupos que lutam por autonomia regional ou independência da Índia, Birmânia e Bangladesh.

43. LTTE significa Liberation Tigers of Tamil Eelam (Tigres de Liberação do Tamil Eelam), uma organização separatista que luta por uma pátria tâmil no norte e leste do Sri Lanka. 


\section{RESUMOS}

Os 'estudos de área' (area studies) usam uma metáfora geográfica para visualizar e naturalizar espaços sociais particulares, bem como uma escala particular de análise. Eles produzem geografias específicas de conhecimento, mas também criam geografias de ignorância. Tomando o Sudeste Asiático como exemplo, neste artigo eu exploro como as áreas são imaginadas e como o conhecimento de área é estruturado para construir 'zonas centrais' (heartlands) e 'zonas de fronteira' (borderlands). Isto é ilustrado considerando-se uma grande região da Ásia (aqui denominada Zomia) que não se tornou uma área mundial na repartição das áreas após a Segunda Guerra Mundial, porque carecia de fortes centros de formação estatal, era politicamente ambígua e não impôs suficiente influência acadêmica. Como Zomia foi esquartejada e tornada periférica pelo surgimento de sólidas comunidades de especialistas de áreas do Leste, Sudeste, Sul e Centro Asiático, a produção de conhecimento sobre ela diminuiu. Sugiro que precisamos examinar mais de perto as políticas acadêmicas de escala que criam e sustentam os estudos de área, em um momento em que a espacialização da teoria social entra em um novo e inexplorado terreno. 0 impulso heurístico por trás das áreas imaginadas e o conhecimento contextualizado, de alta qualidade, que os estudos da área produzem podem ser aproveitados para imaginar outras configurações espaciais, como áreas de 'cortes transversais', o favo de mel mundial das zonas de fronteiras, ou as geografias do processo de fluxos transnacionais. Estudiosos de todas as áreas convencionais podem estar envolvidos neste projeto para 'saltar escala' e desenvolver novos conceitos de espaço regional.

'Area studies' use a geographical metaphor to visualise and naturalise particular social spaces as well as a particular scale of analysis. They produce specific geographies of knowing but also create geographies of ignorance. Taking Southeast Asia as an example, in this paper I explore how areas are imagined and how area knowledge is structured to construct area 'heartlands' as well as area 'borderlands'. This is illustrated by considering a large region of Asia (here named Zomia) that did not make it as a world area in the area dispensation after World War 2 because it lacked strong centres of state formation, was politically ambiguous, and did not command sufficient scholarly clout. As Zomia was quartered and rendered peripheral by the emergence of strong communities of area specialists of East, Southeast, South, and Central Asia, the production of knowledge about it slowed down. I suggest that we need to examine more closely the academic politics of scale that create and sustain area studies, at a time when the spatialisation of social theory enters a new, uncharted terrain. The heuristic impulse behind imagining areas, and the high-quality, contextualised knowledge that area studies produce, may be harnessed to imagine other spatial configurations, such as 'crosscutting' areas, the worldwide honeycomb of borderlands, or the process geographies of transnational flows. Scholars of all conventional areas can be involved in this project to 'jump scale' and to develop new concepts of regional space.

Les area studies utilisent une métaphore géographique pour visualiser et naturaliser des espaces sociaux particuliers, ainsi qu'une échelle d'analyse particulière. Ils produisent des géographies spécifiques du savoir mais créent aussi des géographies de l'ignorance. En prenant l'Asie du SudEst comme exemple, dans cet article, j'explore comment les zones (areas) sont imaginées et comment la connaissance de la zone est structurée pour construire des « centres » ainsi que des « zones frontalières ». Ceci est illustré en considérant une grande région d'Asie (ici nommée Zomia) qui n'en est pas devenue une zone mondiale après la Seconde Guerre mondiale car elle manquait de centres forts de formation d'État, était politiquement ambiguë et ne disposait pas d'un poids scientifique. Alors que Zomia était écartelée et rendu périphérique par l'émergence de fortes communautés de spécialistes de zone d'Asie de l'Est, du Sud-Est, du Sud et Centrale, la 
production de connaissances à son sujet s'est ralentie. Je suggère que nous devons examiner de plus près les politiques académiques qui créent et soutiennent les études régionales, à un moment où la spatialisation de la théorie sociale pénètre un nouveau terrain inexploré. L'impulsion heuristique derrière l'imagination des zones, et la connaissance contextualisée que produisent les area studies, peuvent être exploitées pour imaginer d'autres configurations spatiales, telles que les zones " transversales », le nid d'abeilles mondial des régions frontalières ou les processus géographiques des flux transnationaux. Les chercheurs de tous les domaines conventionnels peuvent être impliqués dans ce projet pour «sauter l'échelle » et développer de nouveaux concepts d'espace régional.

Los "estudios de área" utilizan una metáfora geográfica para visualizar y naturalizar espacios sociales particulares, así como una escala de análisis particular. Producen geografías específicas de conocimiento, pero también crean geografías de ignorancia. Tomando el sudeste asiático como ejemplo, en este artículo exploro cómo se imaginan las áreas y cómo se estructura el conocimiento de áreas para construir áreas centrais (heartland) así como áreas de fronteras (borderland). Esto se ilustra al considerar una gran región de Asia (aquí llamada Zomia) que no la convirtió en un área mundial en la dispensación del área después de la Segunda Guerra Mundial porque carecía de centros fuertes de formación estatal, era políticamente ambigua y no tenía suficiente influencia académica. A medida que Zomia fue descuartizada y convertida en periférica por el surgimiento de fuertes comunidades de especialistas de área del este, sureste, sur y centro de Asia, la producción de conocimiento al respecto se ralentizó. Sugiero que debemos examinar más de cerca las políticas académicas de escala que crean y sustentan los estudios de área, en un momento en que la espacialización de la teoría social entra en un terreno nuevo e inexplorado. El impulso heurístico detrás de la imaginación de áreas, y el conocimiento contextualizado de alta calidad que producen los estudios de áreas, pueden aprovecharse para imaginar otras configuraciones espaciales, como "áreas transversales", el panal mundial de fronteras o las geografías de proceso de los flujos transnacionales. Estudiosos de todas las áreas convencionales pueden participar en este proyecto para "saltar de escala" y desarrollar nuevos conceptos de espacio regional.

\section{ÍNDICE}

\section{Índice cronológico: Século XX}

Palavras-chave: estudos de área, Zomia, Sudeste Asiático, escala, produção de conhecimento

Palabras claves: estudios de área, Zomia, Sudeste de Asia, escala, producción de conocimiento

Índice geográfico: Sudeste da Ásia

Keywords: area studies, Zomia, Southeast Asia, scale, production of knowledge

Mots-clés: area studies, Zomia, Asie du Sud-Est, échelle, production de la connaissance

\section{AUTOR}

\section{WILLEM VAN SCHENDEL}

Estudos Asiáticos, Universidade de Amsterdã. E-mail: H.W.vanSchendel@uva.nl 